\title{
Accesibilidad y territorio histórico en Italia: estrategias resilientes para la revitalización, entre ferrocarriles secundarios y redes paisajísticas
}

\author{
Chiara Ravagnan ${ }^{1} \mid$ Mario Cerasoli ${ }^{2}$ | Bruno Monardo ${ }^{3}$ | Carlo Valorani ${ }^{4}$
}

Recibido: 29-11-2020 | en su versión final: 31-05-2021

Resumen

\begin{abstract}
El tema de la revitalización de los centros históricos menores involucra el tema de la accesibilidad como condición de resiliencia y como componente fundamental de las estrategias de regeneración. Por un lado, las políticas territoriales prestan atención al transporte colectivo como una evolución interpretativa del "derecho a la ciudad", para garantizar la habitabilidad y la inclusión social y reactivar economías en los territorios desfavorecidos. Además, las líneas estratégicas internacionales reconocen la connotación de las infraestructuras históricas (ferrocarriles históricos, rutas de trashumancia) como bienes comunes capaces de trazar una reconfiguración morfológica y poner en valor el paisaje. En este contexto, las redes de infraestructura capaces de reconectar los pequeños centros históricos representan un interesante campo de investigación en el marco de enfoques integrados y multiescalares. El artículo desarrolla una reflexión sobre las oportunidades que ofrece la movilidad sostenible para la mejora de los territorios periféricos italianos, desde sus raíces culturales hasta el patrimonio natural y construido y el layout socioeconómico. El análisis profundiza estudios de casos en los que la dimensión intermunicipal es la referencia emblemática para enfoques integrados y multiescalares que se basan en la centralidad de la planificación de la movilidad. En estos casos, las estrategias de regeneración se activan mediante la conexión en red del territorio histórico y el fortalecimiento de los enlaces infraestructurales, poniendo en valor las directrices morfológicas y las redes paisajísticas.
\end{abstract}

Palabras clave: Infraestructuras de movilidad; centros históricos; movilidad; resiliencia

Citación

Ravagnan C. et al. (2021). Accesibilidad y territorio histórico en Italia: estrategias resilientes para la revitalización, entre ferrocarriles secundarios y redes paisajísticas. ACE: Architecture, City and Environment, 16(46), 9890. DOI: http://dx.doi.org/10.5821/ace.16.46.9890

\section{Accessibility and Historical Territory in Italy: Resilient Strategies for Revitalization, Between Secondary Railways and Landscape Networks}

Abstract

\begin{abstract}
The issue of the revitalization of minor historical centres involves the theme of accessibility as a condition of resilience and as a fundamental component of regeneration strategies. On the one hand, territorial policies pay attention to collective transport as an interpretative evolution of the "right to the city", to guarantee liveability and social inclusion and reactivate economies in disadvantaged territories. In addition, the international strategic lines recognize the connotation of historical infrastructures (historical railways, transhumance routes), as common goods capable of tracing a morphological reconfiguration and enhancing the landscape. In this context, infrastructure networks enable the reconnection of small historic centres between each other and with the dynamics territories. Furthermore, infrastructure networks represent an interesting field of Italian research in the context of integrated and multi-scalar approaches. The paper develops a reflection on the opportunities offered by sustainable mobility for the improvement of the Italian peripheral territories, from its cultural roots to the natural and built heritage and to the socio-economic structure. The analysis deepens the Italian case studies in which the inter-municipal dimension is the emblematic reference for integrated and multi-scale approaches that are based on the centrality of mobility planning. In these cases, the regeneration strategies are activated through the network connection of the historic territory and the strengthening of the infrastructure links, enhancing the morphological guidelines and the landscape networks.
\end{abstract}

Keywords: Mobility infrastructure; historic centres; mobility; resilience

1 Investigadora y docente, Sapienza Università di Roma (ORCiD: 0000-0002-6036-1313, ResearcherID: ABF2243-2020; Scopus Author ID: 57191847896), ${ }^{2}$ Profesor Asociado, Università degli Studi Roma Tre (ORCiD: 0000-0001-5891-4049), ${ }^{3}$ Profesor Asociado, Sapienza Università di Roma (ORCiD: 0000-0003-2787-6259, Scopus ID: 57201733842), ${ }^{4}$ Profesor Asociado, Sapienza Università di Roma (ORCiD: 0000-0002-7139-9552; ResearcherID: ABF-3393-2020; Scopus ID: 57217157551). Correo de contacto: chiara.ravagnan@uniroma1.it

ACE, 16 (46) CC BY-ND 3.0 ES | UPC Barcelona, España | Accesibilidad y territorio histórico en Italia: estrategias resilientes para la revitalización, entre ferrocarriles secundarios y redes paisajísticas. DOI http://dx.doi.org/10.5821/ace.16.46.9890 


\section{Introducción. Los desafíos para los centros menores en el territorio histórico entre shrinkage y regeneración}

Desde hace algún tiempo en el debate sobre las políticas de gobierno del territorio, el tema de la revitalización de las antiguas aldeas y de los centros históricos menores en Italia ha dejado de ocupar una posición de retaguardia para adquirir una mayor visibilidad en la agenda de la administración pública central y de las entidades locales, entre cuyos cometidos figura el de conjugar las expectativas legítimas de las comunidades cívicas entre instancias de relanzamiento socioeconómico y la salvaguarda de las identidades histórico-culturales (Barca et al., 2014; Mibact, 2020).

La dificultad y la heterogeneidad de la condición en la que se articulan los denominados "centros históricos menores" queda muy bien reflejada en la clasificación en tres categorías de asentamientos históricos que propuso Pier Luigi Cervellati. Esta clasificación divide los centros en "encapsulados" en la expansión urbana y en la agricultura industrializada, "abandonados" por razones naturales (fenómenos sísmicos, problemas de asentamiento del terreno) o por la creación de nuevos asentamientos y "transfigurados" por la recuperación homologada del turismo (Cervellati, 2009). Una distinción que revela sutil y eficazmente los principales puntos críticos de los centros históricos menores: el aislamiento por escasa accesibilidad y ausencia de conexión a las "redes largas" de los territorios más amplios, el empobrecimiento del tejido productivo, la degradación del patrimonio histórico-artístico y edificatorio, la despoblación y el envejecimiento rápido de la población (Cerasoli, 2017; Palazzo, 2017).

Los datos elaborados por el ISTAT (Instituto Nacional de Estadística) ponen de manifiesto la importancia del fenómeno de los municipios pequeños: en 2019 el 69,43\% (5.500 municipios) tenía menos de 5.000 habitantes. El conjunto de estos municipios corresponde al $54 \%$ de la superficie nacional, pero sólo al 17\% de la población. Además, la ANCl - Asociación Nacional Municipios Italianos - aclara en su Atlas de los municipios pequeños (Figura 1) que si por un lado aun escasean los fenómenos de contra-éxodo (recuperación demográfica) a los municipios pequeños (sobre todo en el Trentino Alto Adige, Lombardía, Valle d'Aosta'), la mayoría de éstos se caracterizan por un declive demográfico.

A pesar de estar distribuidos en territorios muy diversificados - como resultado de dinámicas de sistemas naturales específicos y de siglos de procesos de antropización - en su mayoría los centros menores se caracterizan por determinados rasgos comunes como la remoteness - la significativa distancia entre éstos y los principales polos de oferta de los servicios esenciales - y la amenity de los recursos culturales y ambientales (Figura 2), que representan un potencial para la producción de servicios ecosistémicos (UN, 2005).

A esta condición de remoteness, además de las características de los asentamientos, contribuyeron mucho las políticas infraestructurales de las últimas décadas, que han alimentado la brecha entre "territorios rápidos" y "territorios lentos", como resultado de unas decisiones tomadas en el marco de las políticas infraestructurales y territoriales (Cerasoli, 2015).

En este contexto, los frentes más avanzados del debate internacional (AAVV, 2017), del que Italia se está convirtiendo en líder europeo, abogan por contrarrestar la decadencia de los territorios de valor cultural y ambiental en los que se emplazan los centros menores, poniendo en el centro de las estrategias de desarrollo sostenible la cuestión de la accesibilidad y sus múltiples dimensiones (OECD, 2013). Por consiguiente, las políticas y los planes están llamados a asumir cada vez más responsabilidades en términos de fortalecimiento de las redes infraestructurales históricas y

${ }^{1}$ Estos son los municipios situados a lo largo las rutas de relaciones internacionales (con Francia, Suiza y Austria-Alemania) que son muy activas a nivel socioeconómico y cultural.

ACE, 16 (46) CC BY-ND 3.0 ES | UPC Barcelona, España | Accesibilidad y territorio histórico en Italia: estrategias

resilientes para la revitalización, entre ferrocarriles secundarios y redes paisajísticas. DOI http://dx.doi.org/10.5821/ace.16.46.9890 
contemporáneas, como bastidores de lugares y relaciones funcionales, morfológicas, paisajísticas, una estructura de referencia indispensable para garantizar el estado del bienestar, el sentido de pertenencia y la inclusión de los colectivos (Ravagnan, Amato, 2020).

Figura 1. Atlas de los municipios pequeños italianos

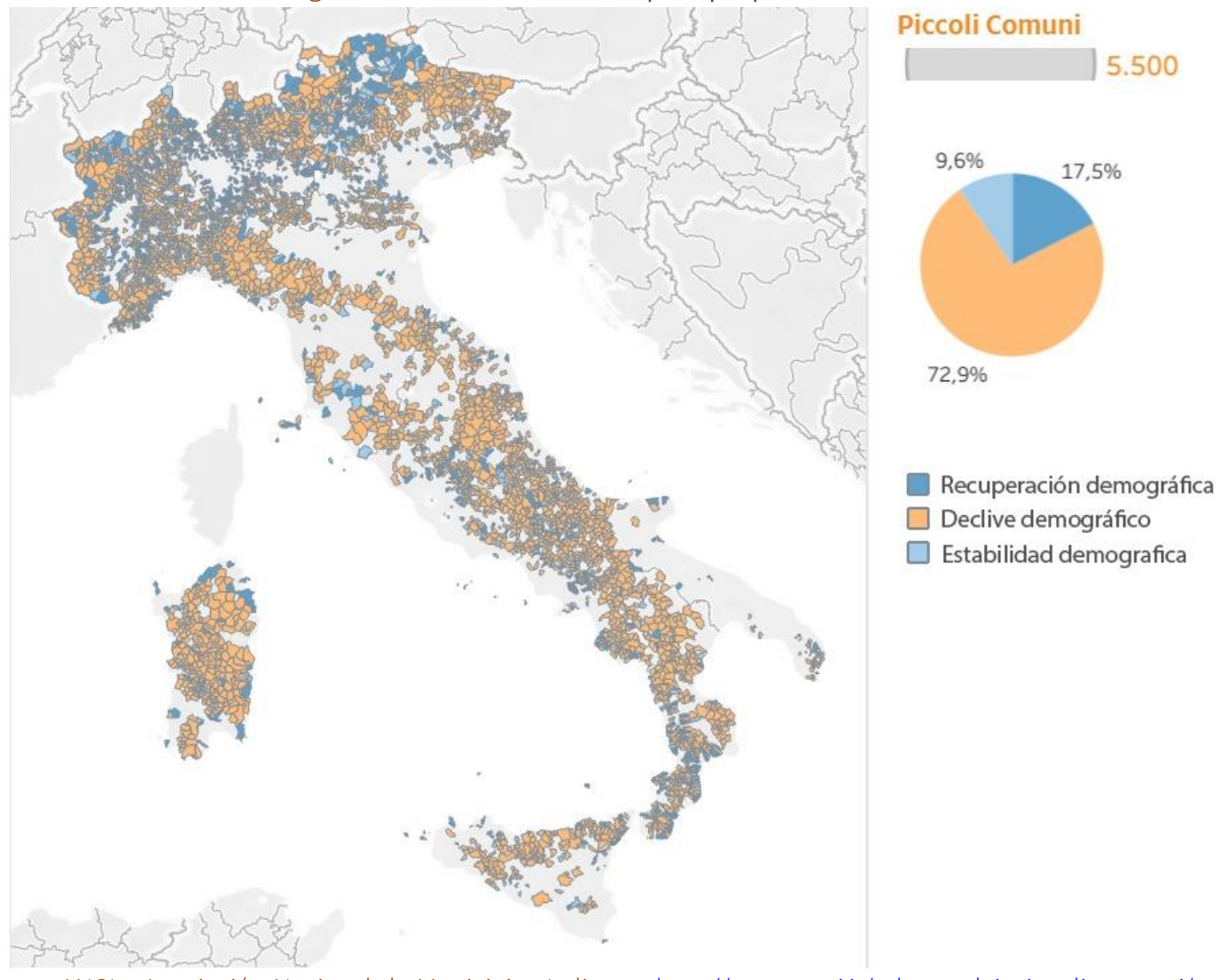

Fuente: ANCl - Asociación Nacional de Municipios Italianos. http://www.anci.it/atlante-dei-piccoli-comuni/ Datos ISTAT.

Figura 2. Centros históricos en las áreas internas: Pettorano sul Gizio (Abruzzo), Caltabellotta (Sicilia) Castelnuovo di Garfagnana (Toscana)

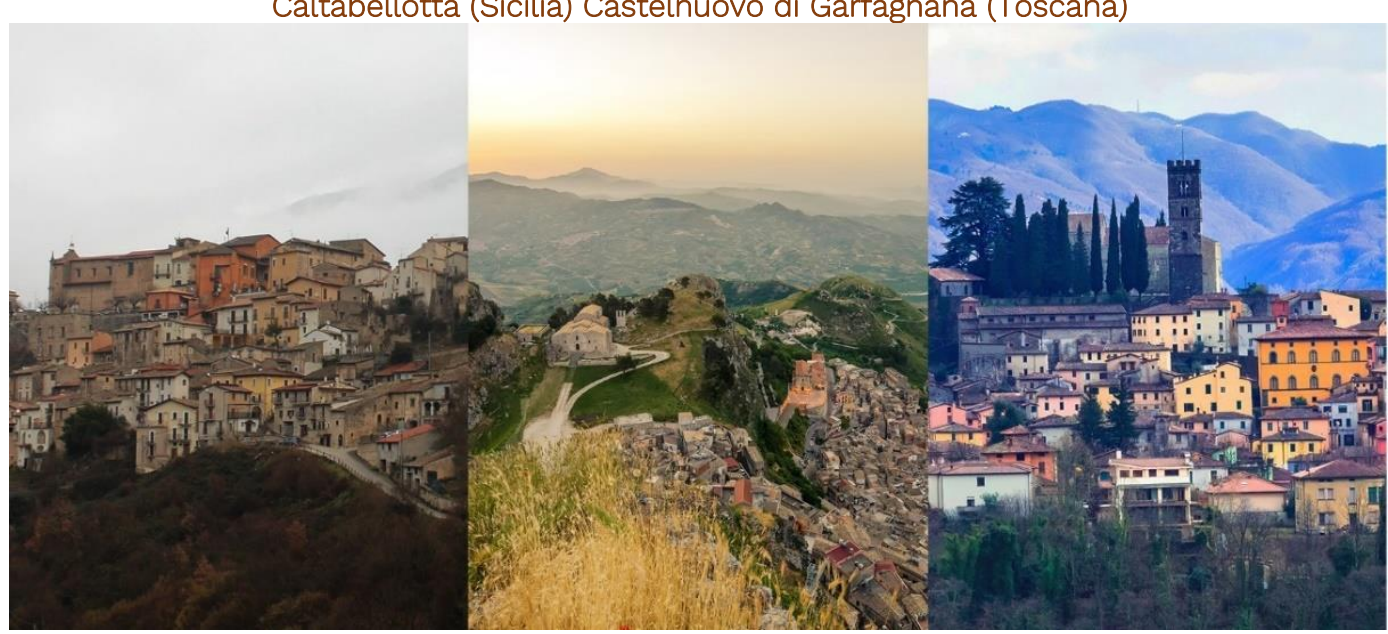

Fuente: C. Ravagnan (a la izquierda), Ph. istock.com/Krivinis (al centro), Ph. istockphoto.com/freeartist (a la derecha).

ACE, 16 (46) CC BY-ND 3.0 ES | UPC Barcelona, España | Accesibilidad y territorio histórico en Italia: estrategias resilientes para la revitalización, entre ferrocarriles secundarios y redes paisajísticas. DOI http://dx.doi.org/10.5821/ace.16.46.9890 
El objetivo central de estas reflexiones es demostrar, mediante referencias a argumentos teóricos de escuelas de pensamiento consolidadas y soluciones comprobadas aplicadas en el marco de la planificación intermunicipal, que el relanzamiento de los territorios que acogen centros históricos menores se realiza insistiendo de forma privilegiada en el proyecto de accesibilidad entendida en todas sus facetas (§ 2). Pero aplicar los principios de una planificación virtuosa de la accesibilidad significa enfatizar la relación sinérgica entre el territorio y modalidades de desplazamiento auténticamente sostenibles. Éste es el caso de las infraestructuras ferroviarias de que se reconstruyen brevemente las principales fases evolutivas en Italia (§ 3) y se ponen después de relieve algunas de sus mejores prácticas; políticas y planes cuyos objetivos de regeneración de los centros históricos y de valorización del patrimonio cultural corren a cargo - de forma privilegiada - del relanzamiento o de la reutilización de las líneas ferroviarias, reconocidas como bastidores consolidados del sistema urbano difuso y como rutas de percepción privilegiada del paisaje (§ 4.; 4.1). Sin embargo, las infraestructuras ferroviarias no agotan las oportunidades de reconectar núcleos históricos y pueblos amurallados en una perspectiva de resiliencia. En la maraña de los antiguos trazados viarios y de las rutas con valor identitario, destaca el papel de las directrices de trashumancia que permiten recuperar la complejidad de los paisajes culturales, como es el caso del Lacio (§ 4.2). La contribución termina confirmando la necesidad de promover un nuevo rumbo en la integración entre planificación de la accesibilidad y estrategias de revitalización de los "territorios interiores", a través del fortalecimiento de las relaciones materiales e inmateriales entre los centros menores y la reactivación de las conexiones con las áreas más dinámicas del país (§ 5).

\section{Accesibilidad y proyectos de territorio}

Los proyectos territoriales relacionados con los ferrocarriles históricos en Italia están vinculados culturalmente a la rica estratificación de los paisajes naturales y de las intervenciones antrópicas surcadas por un denso sistema de redes de transporte desarrolladas tanto en las antiguas líneas ferroviarias como en las carreteras, las vías fluviales, las rutas de la trashumancia. Esta condición es común a países europeos que son similares a Italia por peculiaridades geomorfológicas, hidrográficas, paisajísticas, culturales y climáticas.

Va más allá de los objetivos de esta contribución realizar un relevamiento crítico-interpretativo del estado del arte de las políticas, estilos y enfoques culturales y de las experiencias internacionales más significativas en el relanzamiento y puesta en valor de las diversas infraestructuras históricas de movilidad y transporte.

A nivel internacional, muchas iniciativas para mejorar las líneas ferroviarias en desuso han puesto de relieve el potencial de este patrimonio y el papel de la gobernanza institucional, en términos de agenda política y programas económicos, destacando la importancia del diálogo entre los responsables políticos, los stakeholders y las comunidades locales. La literatura científica sobre el tema es vasta, sin embargo, parece evidente que una categorización sistemática y compartida de las infraestructuras históricas de movilidad y transporte sigue siendo un asunto sustancialmente sin resolver. Las principales iniciativas se remontan a dos métodos recurrentes de reutilización: por un lado, el modelo de vías verdes, o la transformación de líneas ferroviarias en desuso en sistemas de movilidad lenta, por otro, su conversión con fines turísticos.

Las vías verdes o greenways son corredores de espacios abiertos que varían mucho en enfoques culturales y dimensiones de escala, que incluyen y conectan recursos naturales, culturales y paisajísticos heterogéneos. En muchos casos representan una oportunidad de revitalización para territorios en declive a través de redes de espacios recreativos y rutas escénicas con movilidad terrestre eco-sostenible (García-Mayor et al., 2020) pero también, entrelazándose con vías fluviales, sistemas de canales históricos ("living waterways"), estudiados con enfoques orientados a la

ACE, 16 (46) CC BY-ND 3.0 ES | UPC Barcelona, España | Accesibilidad y territorio histórico en Italia: estrategias 4 resilientes para la revitalización, entre ferrocarriles secundarios y redes paisajísticas. DOI http://dx.doi.org/10.5821/ace.16.46.9890 
dimensión del meta proyecto para incrementar los servicios ecosistémicos de carácter social, económico y recreativo de las comunidades locales (Al Dwairi, 2020); en otros casos pasan a formar parte de "redes verdes y azules" más amplias, perseguidas casi exclusivamente para la protección del medio ambiente y de los recursos territoriales.

En las greenways desde los años 90 en Europa, se han registrado experiencias significativas en las que se han creado redes a escala nacional, lo que ha tenido como resultado impactos en términos de sostenibilidad, potenciación turística y nueva movilidad. Bastará recordar las Vías Verdes en España, las Ecopistas en Portugal, el proyecto RAVeL en Bélgica, el Programa Sustrans en Reino Unido. Una caracterización específica en contextos estadounidenses, pero también en ejemplos europeos y de otros continentes, es la transformación de conexiones ferroviarias en desuso en "trail rails", rutas largas para uso turístico ecológico para movilidad suave, peatonal, ciclista y a caballo (Conlin, Bird, 2014) que salvaguardan los valores naturales de los territorios y preservan las sedes preexistentes para posibles futuras reutilizaciones sinérgicas.

El segundo modelo suele tener como objetivo dar un nuevo ciclo de vida a los ferrocarriles históricos que atraviesan territorios de valor; estas son estrategias de calidad que han vuelto a proponer de manera convincente la simbiosis entre sorprendentes artefactos de infraestructura y extraordinarios paisajes naturales: una feliz combinación hasta el punto de merecer legítimamente la inclusión en el patrimonio de la UNESCO (Coulls, 1999), como en las vías de ferrocarril históricas convertidas para uso turístico del Semmering, en Austria, y de la Línea Rética, entre Italia y Suiza, protegidos respectivamente desde 1998 y 2008. Estas experiencias, recuperando y mejorando el patrimonio ferroviario existente de forma coherente con un enfoque "place-based" (Barca, 2009), puede tener impactos positivos en el territorio al contribuir a sistematizar los recursos culturales, históricos, económicos y sociales. En definitiva, el tren, en su transformación de infraestructura a vector de promoción y uso del territorio, cataliza una demanda creciente en el sector turístico, tanto a nivel nacional como internacional (Taylor, 2015).

Junto a la realidad aún más densa y articulada de las políticas y estrategias que persiguen la recuperación y puesta en valor de caminos y de las rutas históricas con valor paisajístico para dar un nuevo impulso a los territorios en declive, todo el rico y complejo palimpsesto de redes que marcan los asentamientos territoriales en Europa y en otros contextos geográficos sorprende por la heterogeneidad de objetivos, usos, modos de movimiento, relaciones con los contextos geográficos y las especificidades de los lugares y representa un precipitado precioso que alimenta los proyectos territoriales. Se puede decir que las estrategias y casos de Italia que se ilustran a continuación (§ 4.1) están unidos por la capacidad de proponer la regeneración de las áreas internas y de los territorios en declive a través de unas claves interpretativas privilegiadas entre las que destaca la accesibilidad, para ser entendida en la riqueza de su facetado tamaño.

El tema de la accesibilidad adquiere una dimensión crucial en las políticas de regeneración de los asentamientos aplicadas tanto a las grandes áreas urbanas como a los territorios con centros históricos menores. Las recientes experiencias a nivel internacional y nacional demuestran en qué medida su gestión en modo más "inteligente" pueda constituir el eje de la identidad de comunidades y grupos sociales cada vez más difíciles de gobernar por su carácter fragmentario y heterogéneo (Touraine, 2008). Una identidad cambiante, que puede delinear modelos sostenibles de policentrismo (físico-espacial y económico, pero también e igualmente cultural y social) donde es posible reajustar, en un juego de geometría variable, el nivel de diálogo, de relación y de cohesión. "Proyectos de territorio" que tengan en cuenta la demanda de urbanidad expresada por una civitas que ya es "fractal" y que utilicen la conectividad - asegurada sobre todo por el transporte colectivo tecnológicamente avanzado y por los espacios reservados a la movilidad ligera - como objetivo para atender a la demanda de relaciones también por parte de los sujetos más desfavorecidos.

ACE, 16 (46) CC BY-ND 3.0 ES | UPC Barcelona, España | Accesibilidad y territorio histórico en Italia: estrategias

resilientes para la revitalización, entre ferrocarriles secundarios y redes paisajísticas. DOI http://dx.doi.org/10.5821/ace.16.46.9890 
Por lo general, "acceder" significa aprovechar oportunidades en un dominio determinado (Litman, 2014). En las evaluaciones de los expertos que intentan unir espacio del movimiento con factores localizadores de las actividades - sobre todo las "polarizadoras" - surge cada vez con más autoridad el papel de la accesibilidad, un criterio polifacético y complejo que llena las lagunas de los enfoques sectoriales, una antigua herencia todavía muy presente en el campo disciplinario y profesional. Se trata en realidad de un concepto polisémico: bien mirado, razonar en términos de accesibilidad es otro eslabón evolutivo natural en el proceso de transición que va del enfoque tradicional técnicofuncional (infraestructuras de la movilidad, "tráfico", servicios de transporte) a una visión orgánica de las dinámicas en la "ciudad de los flujos” (Dupuy, 1991; Mongin, 2013).

Explorando los recorridos heurísticos, sobre todo de la literatura científica más evolucionada y consolidada sobre el tema, destaca la aportación de la "escuela francesa" (Offner y Pumain, 1996; CERTU, 2011) que pone de relieve tres dimensiones de la accesibilidad: la geográfico-espacial, la ergonómica y la social.

La dimensión geográfico-espacial es la más intuitiva y en cierto sentido, "tradicional", en el campo disciplinario: acceder en virtud de la posibilidad de llegar a un lugar, a un punto exacto del espacio, del territorio entendido como dominio específico de referencia; acceder como posibilidad de atender a la demanda de movilidad, beneficiarse de la oferta de bienes, de servicios, de capital humano, de "materia urbana" condensada en lugares que la colectividad pone a disposición de cada "usuario de la ciudad".

En los asentamientos cada comunidad virtuosa ambiciona niveles de excelencia de las redes de movilidad y de los sistemas de transporte colectivo, capaces de atender a la creciente demanda de accesibilidad espacial expresada por una civitas cada vez más "líquida" y fractal. Sin embargo, sería demagógico, además de utopista, perseguir una accesibilidad privilegiada más o menos "ubicuitaria" dentro de la franja de referencia de una realidad urbana, metropolitana o territorial compleja.

En la declinación espacial, la accesibility planningelaborada según los distintos umbrales de lo urbano (desde los pequeños y medianos centros a las grandes metrópolis), conlleva una actitud selectiva: se trata de tomar una decisión consciente y responsable a la hora de definir los destinos considerados irrenunciables para construir (o relanzar) la cohesión de urbs y civitas, reconociendo la identidad también a través de la conexión privilegiada desde y hacia los "polos de excelencia" de la ciudad.

Garantizar la accesibilidad geográfico-espacial significa favorecer la concentración o la difusión por clusters de las oportunidades, ajustando flujos y oferta de servicios de transporte según el factor de escala o tomando como referente el caleidoscopio de la demanda expresada por las distintas categorías de los sujetos. La mejora de la accesibilidad pasa por acciones selectivas respecto a los caracteres específicos de las condiciones locales: desde la re-localización de concentración de equipamientos de interés general en ámbitos residenciales excéntricos, hasta la densificación de servicios, pasando por el incremento de la performance del transporte colectivo (velocidad comercial, comodidad, frecuencia, seguridad) en las directrices primarias para favorecer el "desenclavement' de zonas físicamente marginadas, donde a menudo se concentran sujetos socialmente desfavorecidos. Hoy día la acepción "ergonómica" de la accesibilidad ha superado con creces las angostas limitaciones relacionadas con la mera aplicación en escala de edificio público (o privado, pero de interés general) mediante prescripciones y normas para favorecer la eliminación de las barreras arquitectónicas.

Desde hace tiempo la World Health Organization, se ha propuesto superar el concepto de "impedimento a la movilidad por discapacidad" basado en lógicas obsoletas de la "persona discapacitada" que tiene que lidiar con el problema de superar las "barreras arquitectónicas" en la

ACE, 16 (46) CC BY-ND 3.0 ES | UPC Barcelona, España | Accesibilidad y territorio histórico en Italia: estrategias

resilientes para la revitalización, entre ferrocarriles secundarios y redes paisajísticas. DOI http://dx.doi.org/10.5821/ace.16.46.9890 
ciudad y en el territorio. Sobre la base de la Classification Internationale du Functionnement du handicap et de la santé (WHO 2001) y del "Plan de acción sobre movilidad urbana" de la Comisión Europea (COM 2009) hoy se puede hablar de "personas con movilidad reducida" en el sentido más amplio del término; esta categoría, además de las personas "con habilidades diferentes" (es decir con cierto grado de discapacidad sensorial o intelectual), incluye otros grupos de personas con impedimentos también temporales, como son los ancianos, las mujeres embarazadas, las personas que cargan con maletas, bultos pesados, carros, adultos que llevan a niños cogiéndolos de la mano o con el cochecito. En los países OCDE se calcula que la totalidad de estos sujetos suman una media del $40 \%$ aproximadamente del total de la población.

El nuevo paradigma conceptual permite poner el foco en las condiciones que ofrecen al individuo la posibilidad de integrarse en la realidad social, eliminando la raíz misma de las causas de impedimento físico-ergonómico en el ambiente urbano. De ahí el papel crucial que el sistema de movilidad y de transporte colectivo asume en la estrategia de la "ciudad accesible", pensado también para atender a las exigencias de la movilidad reducida. La revisión del diseño del espacio para el movimiento demuestra ser más convincente confiriéndole valor a la continuidad física, incentivando la permeabilidad y penetrabilidad del sistema de movilidad peatonal y mejorando la gestión de los flujos a través del proyecto de los sistemas de terminales en los nudos intermodales.

El centro de la cuestión se desplaza hacia la libertad de movimiento y la fluidez de recorrido en el espacio construido. Al objeto de que cualquier ciudadano (con movilidad ordinaria o reducida) pueda disponer de forma exhaustiva de todas las oportunidades que le ofrece la ciudad, habrá que favorecer al máximo la libertad de movimiento, la relación mutua entre los lugares identitarios de la urbes y del territorio, la permeabilidad física del sistema de los espacios públicos que comunican los lugares de "condensación colectiva" basados en actividades polarizadoras, la percepción del espacio urbano, del territorio y del paisaje, a partir de sus hitos históricos y de sus atractivos visuales naturales.

En la tercera declinación, la idea de accesibilidad tiene vínculos profundos e incidencias relevantes en el tema de la equidad social, eje de las políticas para una ciudad que aspira a ser auténticamente inclusiva. Los niveles de calidad según los cuales individuos y grupos sociales "acceden” a lugares, actividades, bienes, servicios e información determinan la nota que marca las oportunidades en el seno de las comunidades cívicas (Monardo, 2014). Las condiciones que privilegian (o excluyen) el acceso pueden configurar una doble asimetría: "horizontal" para un solo individuo, y "vertical" si se refiere a grupos; se trata de desigualdades muy marcadas en épocas de crisis económicas, cuando clases sociales enteras retroceden hacia condiciones de inusual indigencia y la presión de los grupos inmigratorios es la que dicta las nuevas necesidades en la relación con las políticas de instituciones, entidades locales y ciudadanías de países y municipios de acogida.

Por tanto, la cuestión de la equidad suele centrarse en la capacidad de facilitar un acceso básico a sujetos físicamente, económicamente y socialmente desfavorecidos. El cometido de las políticas sociales en el gobierno "inteligente" de la ciudad es cuidar a los individuos, a los núcleos familiares, a aquellos grupos que por sí solos no pueden alcanzar esos "niveles esenciales" de calidad de los servicios debido a las barreras físicas, económicas, sociales y culturales.

Con el recrudecimiento de la crisis económica internacional, los espacios de maniobra y disponibilidad de recursos, tanto a nivel central como a escala local, para los actores institucionalmente encargados de incentivar las políticas de equidad y de relaciones, han ido menguando drásticamente en los últimos años. En este sentido, los centros menores representan un recurso: paradójicamente pueden contar con la exigua masa crítica para recurrir a políticas de cooperación intermunicipal y a capacidad de gestión flexible y creativa, precisamente en razón de la riqueza, de la difusión y de la especificidad de su patrimonio territorial (Briatore, 2011). Las formas de

ACE, 16 (46) CC BY-ND 3.0 ES | UPC Barcelona, España | Accesibilidad y territorio histórico en Italia: estrategias resilientes para la revitalización, entre ferrocarriles secundarios y redes paisajísticas. DOI: http://dx.doi.org/10.5821/ace.16.46.9890 
incentivación de la accesibilidad social no pueden dejar de formar parte del contexto más general de las políticas contra la marginación, dirigidas a todos los sujetos en situación de vulnerabilidad y debilidad. A través de estrategias de "acupuntura social" y mejora de la accesibilidad periférica se pueden detener con mayor eficacia las lógicas localizadoras tradicionales de los sujetos recesivos, que naturalmente tienden a asentarse en ámbitos territoriales excéntricos o difusos o, por lo general, en aquellas zonas donde degradación e inaccesibilidad espacial son más problemáticos. Responder a las instancias relativas al "derecho a la accesibilidad" - ramal subyacente, en cierto sentido, al tema del "derecho a la ciudad" (Lefebvre, 1968) - significa actuar concretamente para romper los enclaves físico-espaciales, sociales y culturales donde suelen refugiarse los distintos clústeres sociales, desencadenando oportunidades concretas de diálogo entre culturas y favoreciendo una "hibridación virtuosa" dentro de una civitas inter-étnica emergente.

\section{Infraestructuras y movilidad. Políticas y perspectivas entre territorios rápidos y territorios lentos}

Cuando en 1861, inmediatamente después de la Unificación de Italia, se hablaba de la cuestión de dotar al país de infraestructuras, los ferrocarriles ocupaban el centro del debate político. El objetivo del Gobierno era favorecer la accesibilidad a todo el territorio nacional, y no sólo a las grandes ciudades, permitiendo así el desarrollo del país y su entrada en el mercado europeo.

Durante los primeros quince años después de la unificación, el entonces Jefe de Gobierno, Camillo Benso, Conde de Cavour - que había ya entendido que los ferrocarriles en un principio eran fundamentales para el Risorgimento y más tarde también para el desarrollo de la Nación unida - y los gobiernos de la Derecha Histórica invierten con gran energía en la construcción de los ferrocarriles. En pocos años la extensión de la red de ferrocarriles italiana alcanza los 7.000 km (Sellari, 2011), sentando las bases de la que será la actual red de ferrocarriles italiana (Figura 3).

Una red que llega a su máxima extensión - casi 23.000 km. - a finales de los Treinta, cuando casi toda la red viaria está todavía sin asfaltar. Una red que se caracteriza por una velocidad operativa relativamente baja, debido a las tecnologías disponible en aquella época, y más todavía a las características físicas de las líneas, que tenían que atravesar territorios de colinas y montañas - y que para contener los gastos debían seguir trazados tortuosos por no construir túneles que habrían resultado enormemente más caras -. Sin embargo, una red que garantizaba niveles de accesibilidad que hoy han quedado en el olvido.

En la Posguerra, con la proclamación de la República, las políticas de reconstrucción de las infraestructuras son complejas y a menudo también incoherentes. En menos de dos décadas se produce un cambio radical en los modelos de movilidad - favorecido además por la aparición de nuevos modelos culturales a nivel del mundo occidental (Cerasoli, 2016) - y desde entonces empieza a su vez el declive progresivo de los ferrocarriles, sobre todo de los secundarios. Todo esto acentúa algunas dinámicas relativas a los asentamientos, que a su vez inciden en las dinámicas demográficas y socioeconómicas que desembocan en éxodos de poblaciones dentro y fuera del país, con el consiguiente abandono de municipios pequeños, sobre todo en los Apeninos y en el sur.

En los treinta años siguientes al final de la Segunda Guerra Mundial, los ferrocarriles van perdiendo competitividad paulatinamente, no alcanzando a sostener la variada y cada vez mayor demanda de transporte de personas y mercancías, mientras que el abultado programa de construcción de autopistas favorece la motorización masiva y el transporte de mercancías por carretera.

ACE, 16 (46) CC BY-ND 3.0 ES | UPC Barcelona, España | Accesibilidad y territorio histórico en Italia: estrategias

resilientes para la revitalización, entre ferrocarriles secundarios y redes paisajísticas. DOI http://dx.doi.org/10.5821/ace.16.46.9890 


\section{ACE Architecture, City and Environment}

Figura 3. Red italiana de ferrocarriles en 1876 y en 1931

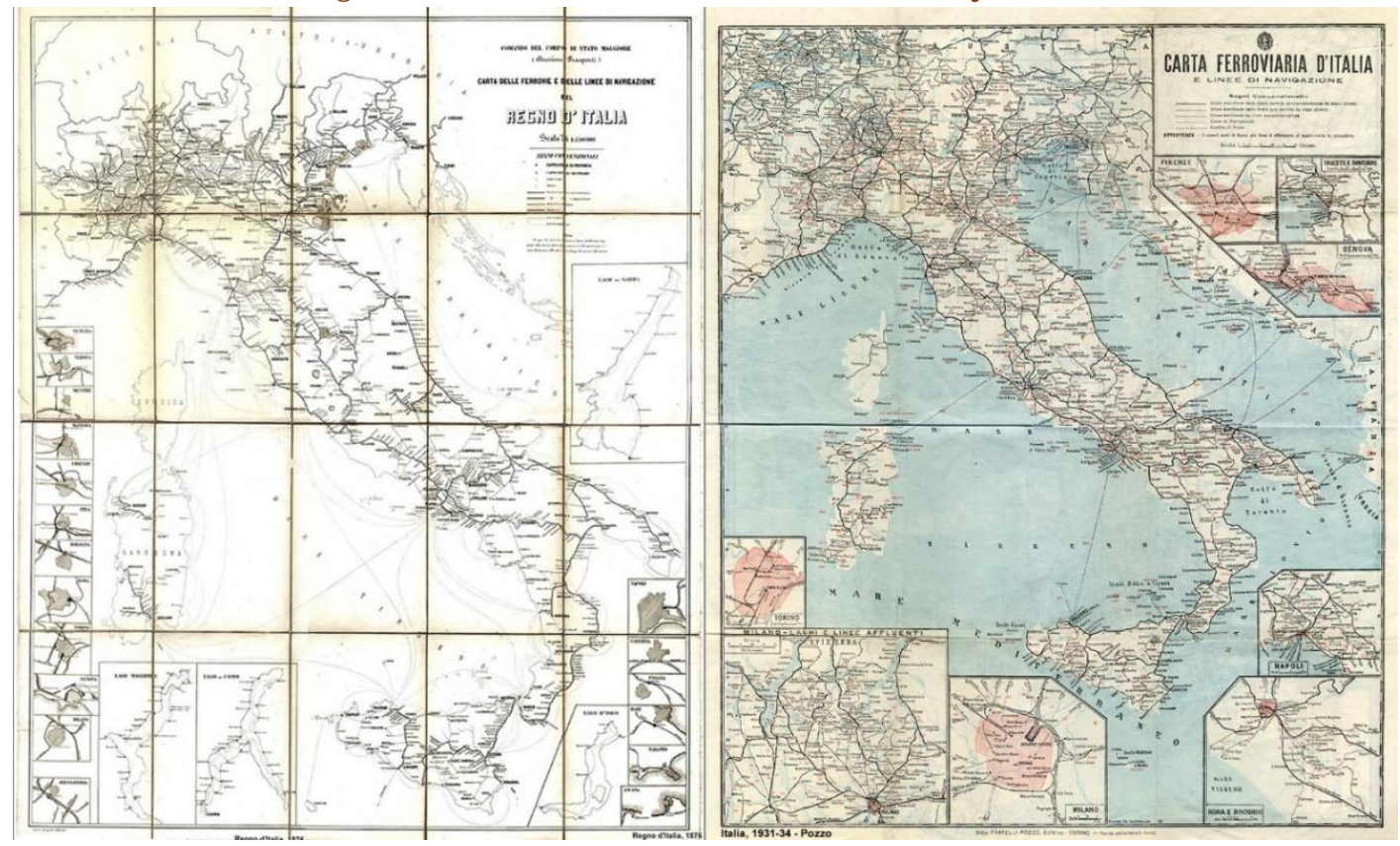

Desde mediados de los Ochenta, como efecto indirecto de los cambios en el carácter jurídico y en la estructura misma de la empresa "Ferrovie dello Stato" - entre otras razones en cumplimiento de la directiva comunitaria $n^{\circ} 440$ de 1991 sobre la liberalización del mercado ferroviario - y la aparición del nuevo tren de Alta Velocidad Turín-Milán-Roma-Nápoles, se abre otra brecha sensible entre los territorios y las ciudades servidas por las líneas principales y por el Tren de Alta Velocidad - los denominados territorios "rápidos" - y los territorios servidos por las líneas secundarias, los territorios “lentos” (Cerasoli, 2015).

Figura 4. Red de ferrocarriles italiana (2018) e identificación de las zonas interiores con la red viaria
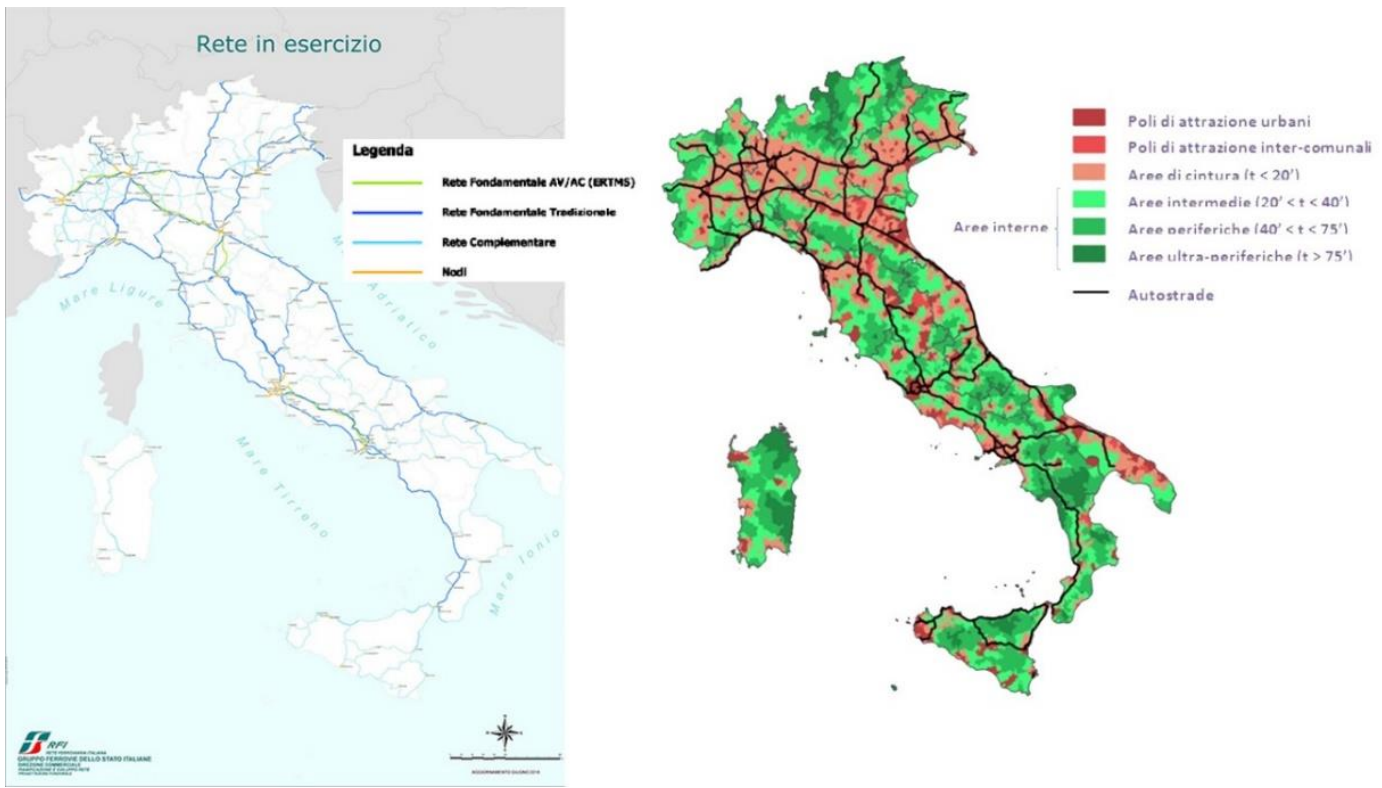

Fuente: RFI y SNAI.

ACE, 16 (46) CC BY-ND 3.0 ES | UPC Barcelona, España | Accesibilidad y territorio histórico en Italia: estrategias resilientes para la revitalización, entre ferrocarriles secundarios y redes paisajísticas. DOI http://dx.doi.org/10.5821/ace.16.46.9890 
En esas mismas décadas, el proceso que llevó al éxodo de los municipios menores se vuelve dramático, hasta tal punto que el Gobierno intenta solucionar el problema instituyendo en 2013 la Agencia para la Cohesión Territorial y aplicando la Estrategia Nacional Áreas Interiores (SNAI). Un proceso que está estrechamente ligado a la reducción de la accesibilidad, derivados, entre otras cosas, de la reducción progresiva de las conexiones ferroviarias en las líneas secundarias (Figura 4). Sin embargo, hoy, en Italia, el potencial de los centros menores se basa precisamente en un patrimonio histórico inmenso que es la envidia de todo el planeta. En una época de gran sensibilidad por los efectos del cambio climático, a partir de esta amplia red de pequeñas ciudades podría arrancar un ambicioso programa de re-equilibrio territorial, que no sólo se puede, sino que se debe sustituir por el relanzamiento de los ferrocarriles secundarios (Mattarocci, 2020). Si por un lado ha habido una forma "tímida" de relanzamiento de estos últimos mediante la Ley 128/2017 "Resoluciones para la institución de ferrocarriles turísticos mediante la reutilización de líneas en desuso, o próximas a ser desafectadas, ubicadas en zonas de valor naturalista o arqueológico especial", por otro lado la aprobación de la Ley "Salva Borghi" (Salva Pueblos Antiguos) representa un paso importante para poner en marcha un proceso de relanzamiento de los territorios "deprimidos" (Mibact, 2020).

\section{La accesibilidad para el relanzamiento sostenible del territorio histórico. Rutas de resiliencia en Italia}

En este contexto, las políticas nacionales reconocen las "áreas interiores" como territorios desligados de los polos de servicios y de los nudos infraestructurales, ámbitos que están desapareciendo pero que son potencialmente resilientes por la presencia de un caudaloso sistema histórico y ambiental ramificado. Este sistema está vinculado a numerosas relaciones a tener en cuenta, en el ámbito de escenarios de "engarce" y de relanzamiento sostenible, donde Italia es líder europeo de nuevas perspectivas de proyecto, también en vistas de la programación 2021-2027.

El debate disciplinario y político sobre las "áreas interiores" italianas cuenta cada vez con un mayor refuerzo internacional en el debate sobre las "inner peripheries" (AAVV, 2017) y los territorios frágiles (Pignatti et al., 2019), abriendo rutas de investigación y de experimentación capaces de atender a una nueva demanda de regeneración urbana y territorial que sepa devolver savia demográfica, económica y cultural a los centros menores y poner en marcha nuevos ciclos de vida para el patrimonio de viviendas e infraestructuras (Amato et al., 2019; Álvarez Mora, 2019; Ravagnan et al., 2021). En particular, la ampliación del campo de atención de la cultura urbanística - que va del "centro histórico" al "territorio histórico" - sancionada con la segunda Carta de Gubbio (ANCSA, 1990), y posteriormente por las referencias promovidas a nivel internacional por la UNESCO con el concepto de "paisaje urbano histórico" (Unesco, 2011) sugieren para estos "territorios sensibles" - que acogen un elevado número de permanencias históricas y naturalistas difusas - una estrategia de resiliencia arraigada en la historia de los lugares y en el patrimonio histórico-cultural. Su localización sobrepasa cada vez con mayor frecuencia las barreras tipológicas, cronológicas, geográficas y jurídicas (Choay, 1992) hasta llegar al reconocimiento de algunos tramos ferroviarios históricos como patrimonio mundial de la Unesco (cfr. §2).

Históricamente, y desde la época más antigua hasta la época moderna, la vivibilidad y el desarrollo económico y cultural de estos territorios, han estado estrechamente ligados a un sistema de redes territoriales, de trazados históricos (como por ejemplo la viabilidad antigua, las redes de trashumancia y las rutas de peregrinaje) y de infraestructuras ferroviarias e hidráulicas. Estas redes sirvieron de bastidor para la construcción del entramado urbano y territorial, por lo que fueron convirtiéndose en partes fundamentales del cuadro de programación territorial (Corboz, 1983) y en rutas privilegiadas de paisajes, como resultado de la interrelación estratificada entre factores naturales y antrópicos

ACE, 16 (46) CC BY-ND 3.0 ES | UPC Barcelona, España | Accesibilidad y territorio histórico en Italia: estrategias 10 resilientes para la revitalización, entre ferrocarriles secundarios y redes paisajísticas. DOI http://dx.doi.org/10.5821/ace.16.46.9890 
(CEP, 2000). Unas redes que a lo largo de los siglos han garantizado la permanencia de aquellas relaciones económicas, sociales y ambientales indispensables para el bienestar de las colectividades (Di Venosa \& Morrica, 2018) y que todavía hoy pueden interpretarse como estructuras de referencia para poner en marcha recorridos de resiliencia (Ravagnan, 2019), al objeto de garantizar una renovada accesibilidad, entendida, como ya hemos dicho, en sus diversas dimensiones: geográfico-espacial, ergonómica y social (cfr. \$2). Una accesibilidad que pueda contribuir a reactivar economías de adaptación a los cambios ambientales y socioeconómicos, a fortalecer la inclusión y a poner de relieve la identidad de los lugares, a través de un carácter del proyecto de territorio necesariamente "proactivo" y dinámico para frenar el deterioro.

En esta perspectiva, es posible integrar y coordinar políticas, planes y proyectos de carácter estructural y estratégico para definir escenarios de valorización de los bienes comunes y de regeneración urbana, ambiental e infraestructural, orientados a sistemas de movilidad resilientes que recuperen las infraestructuras abandonadas o infrautilizadas y los trazados históricos como elementos ordenadores del territorio y componentes estructuradores de los paisajes urbanos y extraurbanos, caracterizados por un patrimonio físico cultural (bienes arqueológicos, centros históricos, abadías, pequeños museos, sistemas agrícolas) y ambientales (recursos hídricos, vegetación, colinas y montañas) y un patrimonio de redes inmateriales (tradiciones constructivas, agro-pastorales, artesanales y artísticas).

Figura 5. La línea Lucca-Aulla, Toscana; el ferrocarril turístico Sulmona-Carpinone "Transiberiano de Italia" y la greenway Via verde dei Trabocchi, Abruzzo

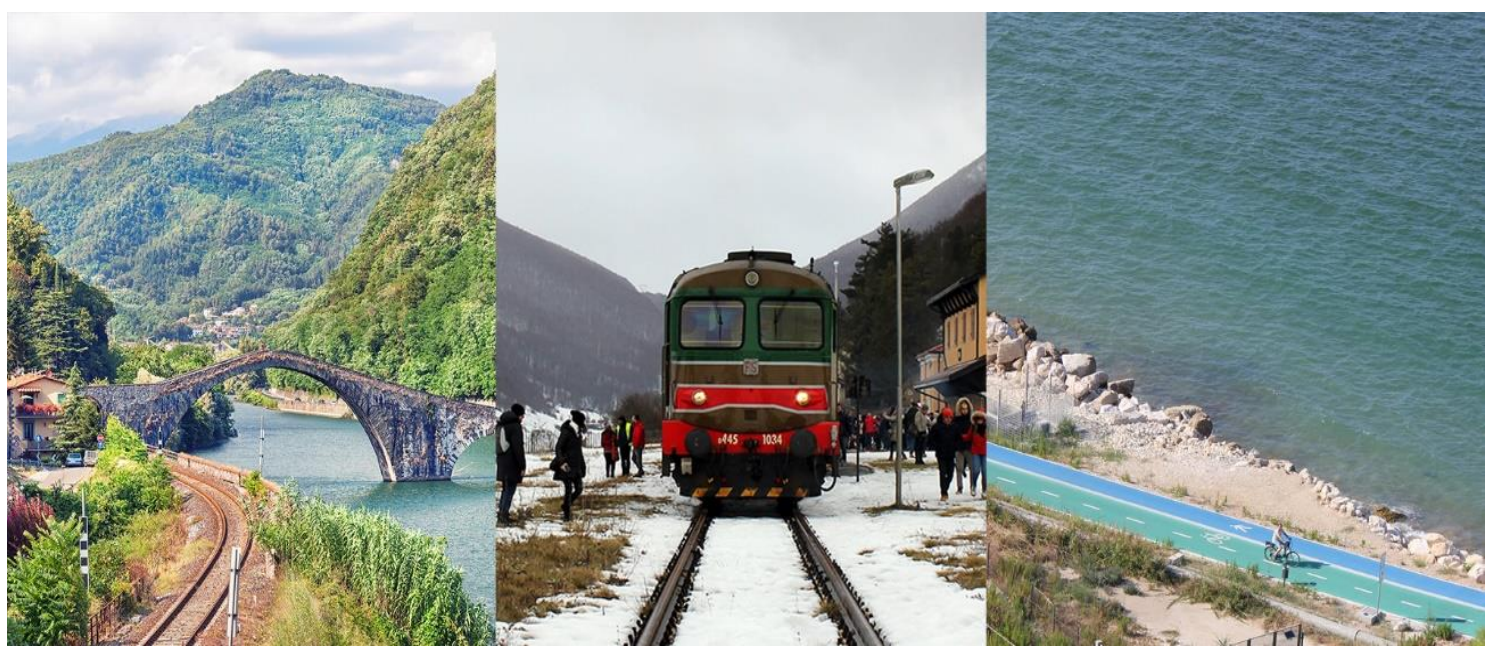

Fuente: Victor Grow (a la izquierda), c. Ravagnan (al centro y a la derecha).

Para dar una nueva vida a estas redes, el proyecto de territorio tiene que combinar objetivos relacionados con el fortalecimiento de las redes físicas, que puedan garantizar el "contra-éxodo" de las poblaciones en el ámbito de formas de movilidad sostenibles ecológica y económicamente y con el fortalecimiento de esos sistemas de redes inmateriales, culturales y sociales, ligados a la historia de los lugares. Un proyecto que sirva para destacar el valor del territorio sin transfigurarlo, aplicando economías (verdes y circulares) pacientes, rentables a largo plazo y que puedan hacer referencia a:

- enfoques multidisciplinarios del territorio y de las infraestructuras, capaces de interpretar la complejidad de las relaciones entre procesos de degradación del territorio, despoblación, crisis económica y abandono de las infraestructuras;

ACE, 16 (46) CC BY-ND 3.0 ES | UPC Barcelona, España | Accesibilidad y territorio histórico en Italia: estrategias

resilientes para la revitalización, entre ferrocarriles secundarios y redes paisajísticas. DOI http://dx.doi.org/10.5821/ace.16.46.9890 
- políticas y estrategias integradas de regeneración que consideren el potencial de las redes infraestructurales antiguas y modernas en términos de calidad, identidad y equidad territorial, teniendo en cuenta los aspectos funcionales y morfológicos, paisajísticos y ambientales, funcionales o de gestión de las infraestructuras y declinando las diferentes dimensiones de la accesibilidad;

- herramientas multiescalares estratégicas y formas de colaboración interinstitucional capaces de operar en territorios con geometría variable con la participación de actores públicos y privados en la planificación, gestión y financiación de las intervenciones en las redes infraestructurales entendidas como bienes comunes en torno a las cuales construir un proyecto de territorio.

\subsection{Las infraestructuras ferroviarias y el territorio histórico de las "áreas interiores"}

La estrategia nacional de las Áreas interiores y las nuevas leyes sobre los Ferrocarriles turísticos han hecho resurgir las cuestiones ligadas al cese de las "ramas secas" del sistema ferroviario italiano, sobre la base del principio de sostenibilidad del desarrollo territorial y del reconocimiento del derecho a la movilidad como derecho de ciudadanía. Estas nuevas referencias han subrayado los caracteres funcionales, pero también identitarios y sociales de las líneas férreas, apoyando escenarios de relanzamiento del servicio ordinario, de relanzamiento, en clave turística, de los trenes históricos en ámbitos con valor paisajístico o de reutilización de las líneas ferroviarias en la forma de vías verdes (cfr. §2). Proyectos que unen de forma intrínseca la intervención en la accesibilidad con un proyecto de territorio en el que participa un sistema de bienes y lugares estratégicos e identitarios - líneas, estaciones, casas cantoneras, viaductos, túneles - en un proceso global de regeneración del territorio histórico.

La complejidad de estos sistemas territoriales de costa, de laderas y a pie de monte, requiere dar respuesta a una necesidad articulada de transporte, tanto turístico como ordinario; aplicando enfoques multidisciplinarios y estrategias de recalificación integradas que contemplen las cuestiones ambientales, sociales y económicas, priorizando formas de uso sostenible de los bienes ambientales y culturales e inclusivo hacia unos usuarios con condiciones físicas o socioeconómicas desfavorecidas.

Por un lado, la Ley 128/2017 ha respaldado nuevos proyectos de tipo asociativo que ya están en marcha, en el marco de la construcción de un Sistema de ferrocarriles turísticos italianos que recorre paisajes identitarios: desde la "Transiberiana d'Italia" (Tabla 1 y Figura 5), denominada así por su contexto montañés nevado prácticamente todo el año, hasta la "Irpinia Express".

La ley 128 ha también impulsado las Regiones, como en el caso de la "Ferrovia pedemontana del Friuli" (Tabla 1 -Figuras 6-7), que es reconocida como parte de una importante directriz territorial y paisajística e involucrada en proyectos de valorización impulsados por la Región Friuli-Venezia-Giulia centrados en la movilidad sostenible turística y ordinaria (Ravagnan, Amato, 2020).

ACE, 16 (46) CC BY-ND 3.0 ES | UPC Barcelona, España | Accesibilidad y territorio histórico en Italia: estrategias

resilientes para la revitalización, entre ferrocarriles secundarios y redes paisajísticas. DOI http://dx.doi.org/10.5821/ace.16.46.9890 


\section{ACE Architecture, City and Environment}

Figura 6. Plan Paesajístico de la Región Friuli-Venezia-Giulia. Sistema de la movilidad dulce. Projecto.

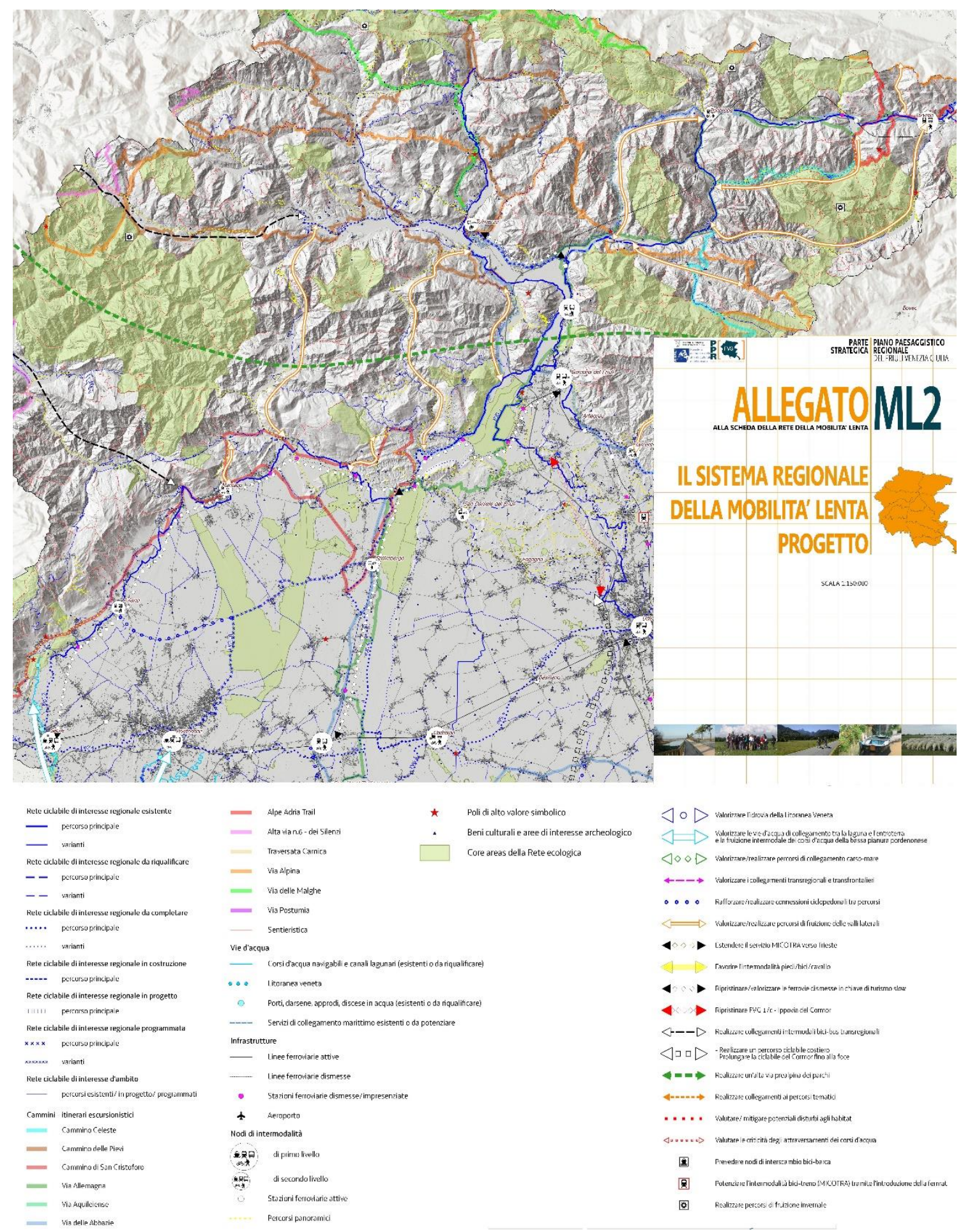

Fuente: Regione FVG https://www.regione.fvg.it/rafvg/cms/RAFVG/ambiente-territorio/pianificazione-gestioneterritorio/FOGLIA21/

ACE, 16 (46) CC BY-ND 3.0 ES | UPC Barcelona, España | Accesibilidad y territorio histórico en Italia: estrategias resilientes para la revitalización, entre ferrocarriles secundarios y redes paisajísticas. DOI http://dx.doi.org/10.5821/ace.16.46.9890 
Tabla 1. Ferrocarriles turísticos italianos (Ley 128/2017)

\begin{tabular}{|c|c|c|c|c|}
\hline Línea & Denominación & $\begin{array}{l}\text { Activatión/ } \\
\text { Cierre/ } \\
\text { Reactivatión }\end{array}$ & $\begin{array}{c}\text { Patrimonio natural } \\
\text { y histórico }\end{array}$ & $\begin{array}{l}\text { Programas \& } \\
\text { Operadores }\end{array}$ \\
\hline $\begin{array}{l}\text { Sulmona-Isernia } \\
\text { (Abruzzo-Molise) }\end{array}$ & Transiberiana d'Italia & 1892/2011/2014 & $\begin{array}{l}\text { Centros históricos } \\
\text { (CS), Parque de la } \\
\text { Majella }\end{array}$ & $\begin{array}{l}\text { Binari senza tempo } \\
\text { (BST), Ass. Le } \\
\text { Rotaie, Fondazione } \\
\text { FS }\end{array}$ \\
\hline $\begin{array}{l}\text { Avellino-Rocchetta } \\
\text { (Campania, Molise, } \\
\text { Puglia) }\end{array}$ & Irpinia Express & $1934 / 1986 / 2016$ & CS, Lago de Conza & $\begin{array}{l}\text { BST, Fondazione } \\
\text { FS, Reg. Campania, } \\
\text { Ass. In_Loco_Motivi }\end{array}$ \\
\hline $\begin{array}{l}\text { Fano - Urbino } \\
\text { (Marche) }\end{array}$ & Ferrovia Valle Metauro & $\begin{array}{l}1898 / 1987 / \\
\text { servicio } \\
\text { suspendido }\end{array}$ & $\begin{array}{l}\text { CS, Rio Metauro, } \\
\text { Costa marina }\end{array}$ & $\begin{array}{l}\text { Ass. Ferrovia Valle } \\
\text { Metauro (FVM) }\end{array}$ \\
\hline $\begin{array}{l}\text { Cosenza-S. Giovanni } \\
\text { F.(Calabria) }\end{array}$ & Ferrovia Silana & 1922/1997/2016 & $\begin{array}{l}\text { CS, Parque de la } \\
\text { Sila }\end{array}$ & FC, Reg. Calabria \\
\hline $\begin{array}{ll}\text { Sacile } & - \\
\text { Gemona(Friuli) }\end{array}$ & $\begin{array}{l}\text { Ferrovia Pedemontana } \\
\text { del Friuli }\end{array}$ & $1914 / 2012 / 2018$ & $\begin{array}{lr}\text { CS, } & \text { Prealpi, } \\
\text { Reserva } & \text { del } \\
\text { Cornino } & \end{array}$ & $\begin{array}{l}\text { BST, RFI } \quad- \\
\text { Fondazione FS }\end{array}$ \\
\hline $\begin{array}{l}\text { Palazzolo-Paratico S. } \\
\text { (Lombardia) }\end{array}$ & $\begin{array}{l}\text { Sebino Express } \\
\text { Treno Blu }\end{array}$ & 1876/1966/1994 & $\begin{array}{l}\text { CS, Oglio Park, } \\
\text { Lago de Iseo }\end{array}$ & $\begin{array}{l}\text { BST, FTI-Ferrovie } \\
\text { turistiche italiane }\end{array}$ \\
\hline $\begin{array}{l}\text { Ceva-Ormea } \\
\text { (Piemonte) }\end{array}$ & Ferrovia del Tanaro & $1883 / 2012 / 2016$ & CS, Rio Tanaro & BST Fondazione FS \\
\hline $\begin{array}{l}\text { Mandas-Arbatax } \\
\text { (Sardegna) }\end{array}$ & Trenino verde & 1893/1997/1997 & $\begin{array}{l}\text { CS,Gennargentu- } \\
\text { Parque de Orosei }\end{array}$ & $\begin{array}{l}\text { ARST(Regione } \\
\text { Sardegna) }\end{array}$ \\
\hline $\begin{array}{l}\text { Isili-Sorgono } \\
\text { (Sardegna) }\end{array}$ & Trenino verde & 1889/1997/1997 & $\begin{array}{l}\text { CS, Gennargentu- } \\
\text { Parque de Orosei }\end{array}$ & $\begin{array}{l}\text { ARST } \\
\text { (Regione Sardegna) }\end{array}$ \\
\hline $\begin{array}{l}\text { Sassari-Palau } \\
\text { (Sardegna) }\end{array}$ & Trenino verde (part) & 1931/1997/1997 & $\begin{array}{l}\text { CS, Liscia Lake, } \\
\text { Costa Marina }\end{array}$ & $\begin{array}{l}\text { ARST } \\
\text { (Regione Sardegna) }\end{array}$ \\
\hline $\begin{array}{l}\text { Macomer-Bosa } \\
\text { (Sardegna) }\end{array}$ & Trenino verde & 1888/1981/1995 & $\begin{array}{l}\text { CS, Rio Temo, } \\
\text { Golfo de Bosa }\end{array}$ & $\begin{array}{l}\text { ARST } \\
\text { (Regione Sardegna) }\end{array}$ \\
\hline $\begin{array}{l}\text { Noto-Pachino } \\
\text { (Sicilia) }\end{array}$ & Ferrovia del vino & $\begin{array}{l}\text { 1935/2002/ } \\
\text { servicio } \\
\text { suspendido }\end{array}$ & $\begin{array}{l}\text { CS, Riserva di } \\
\text { Vendicari }\end{array}$ & FS \\
\hline $\begin{array}{l}\text { Alcantara-Randazzo } \\
\text { (Sicilia) }\end{array}$ & / & $\begin{array}{l}\text { 1959/1985/ } \\
\text { servicio } \\
\text { suspendido }\end{array}$ & $\begin{array}{l}\text { CS, Parque del } \\
\text { Etna, Costa Marina }\end{array}$ & FS \\
\hline $\begin{array}{ll}\text { Castelvetrano- } & \text { P. } \\
\text { Empedocle(Sicilia) }\end{array}$ & Ferrovia dei Templi & $1910 / 1976 / 2014$ & $\begin{array}{l}\text { CS, Costa marina, } \\
\text { Emplazamneto } \\
\text { arqueologico }\end{array}$ & Fondazione FS \\
\hline $\begin{array}{l}\text { Asciano-Monte } \\
\text { Antico (Toscana) }\end{array}$ & $\begin{array}{l}\text { Ferrovia della Val } \\
\text { d'Orcia }\end{array}$ & $1865 / 1994 / 2014$ & $\begin{array}{l}\text { CS, Val d'Orcia, } \\
\text { Parque del Amiata }\end{array}$ & $\begin{array}{l}\text { Ferrovie della Val } \\
\text { d'Orcia }\end{array}$ \\
\hline $\begin{array}{l}\text { Civitavecchia-Orte } \\
\text { (Lazio) }\end{array}$ & l & $\begin{array}{l}\text { 1894/1961/ } \\
\text { servicio } \\
\text { suspendido }\end{array}$ & CS, Costa marina & FS \\
\hline
\end{tabular}

Fuente: Elaboración propia a partir de distintas fuentes: base de datos Ferrovie Abbandonate, Associazione Greenways Italia Onlus y Associazione FIT Ferrovie Turistiche Italiane.

Además, La ley ha impulsado servicios turísticos como el "Ferrocarril della Val d'Orcia" (Tabla 1), gracias a atrevidos viaductos y túneles, discurre por un paisaje cultural constituido por cárcavas y amplios valles agrícolas - con viñedos, olivares, cipreses, bosques de hayas y castaños interrumpidos por antiguas aldeas medievales, casas rurales y burgos con torres abruptas, expresión de una armonía entre el hombre y la naturaleza característica del Renacimiento y celebrada por la Escuela de Siena.

ACE, 16 (46) CC BY-ND 3.0 ES | UPC Barcelona, España | Accesibilidad y territorio histórico en Italia: estrategias 


\section{ACE Architecture, City and Environment}

Figura 7. La Línea Sacile-Gemona (Pedemontana del Friuli), Friuli-Venezia-Giulia

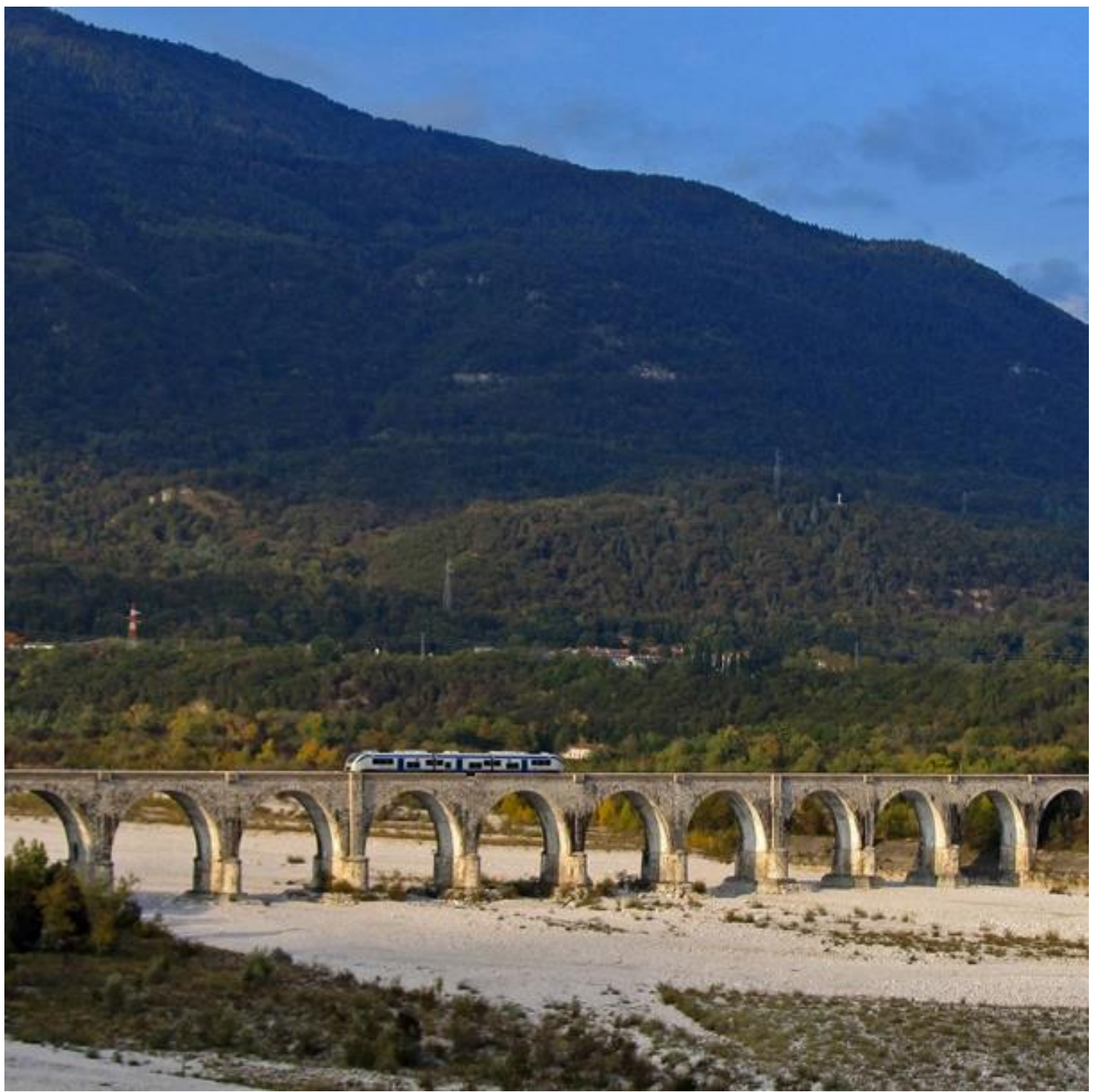

Fuente: Antonio Martinetti.

Por otro lado, la SNAI, en el marco de sus líneas maestras para todo lo que requiere el transporte (Tabla 2), ha promovido unos enfoques y unas estrategias al objeto de realizar modelos "inteligentes" de integración y optimización entre las diferentes formas de movilidad capaces de ahorrar tiempo en la duración del trayecto, y de desarrollar la inter-modalidad o activar nuevas sinergias territoriales con el despliegue de servicios polifuncionales, tanto ordinarios como turísticos. Las intervenciones proponían también la restauración o la puesta en valor de numerosas estaciones (Áreas interiores Sur-oeste Orvienta y Garfagnana-Lunigiana-Mediavalle del Serchio-Apenino pistoyano), y la creación de "hubs intermodales" (Área interior Valdarno y Valdisieve, Mugello, Val Bisenzio y Área interior del Gargano). Las Estrategias contemplan además la reutilización de los ferrocarriles mediante la construcción de vías verdes, como auténtico "proyecto-bandera” del desarrollo local que apunta al reciclado y a la lentitud como criterio de resiliencia, como es el caso del Área interior de los Sicani (Carubia et al, 2015).

ACE, 16 (46) CC BY-ND 3.0 ES | UPC Barcelona, España | Accesibilidad y territorio histórico en Italia: estrategias

resilientes para la revitalización, entre ferrocarriles secundarios y redes paisajísticas. DOI http://dx.doi.org/10.5821/ace.16.46.9890 
Las Estrategias de Área tienen en común una visión integrada en el sistema transporte-territorio que pueda recurrir a herramientas de planificación y programación de tipo estratégico, compartido en vertical por los sujetos institucionales y apoyado por el refuerzo de las coaliciones intermunicipales permanentes capaces de potenciar el poder administrativo y de gestión de los pequeños municipios. En las mejores prácticas, las estrategias de área actúan en coordinación con otras herramientas, como es el caso de la Unión de los Municipios de la Garfagnana, que además de coordinar el trabajo relativo a la Estrategia de Área interior, ha puesto en marcha el Plan intermunicipal con valor de Plan estructural municipal y de Plan estratégico de área amplia, con arreglo a la Ley Regional Toscana 65/2014 Norme per il Governo del Territorio.

Las estrategias de desarrollo sostenible del Plan traducen los objetivos de accesibilidad a través de la integración entre ferrocarriles, carreteras y rutas de valor cultural, reforzando la histórica estructura "de espina" que enlaza la estructura policéntrica de los núcleos históricos (Figura 8).

Figura 8. El Plan intermunicipal con valor de Plan estructural municipal y de Plan estratégico de la Union de los Municipios de la Garfagnana. P03 - I - strategie mobilità e sistema insediativo (Leyenda)

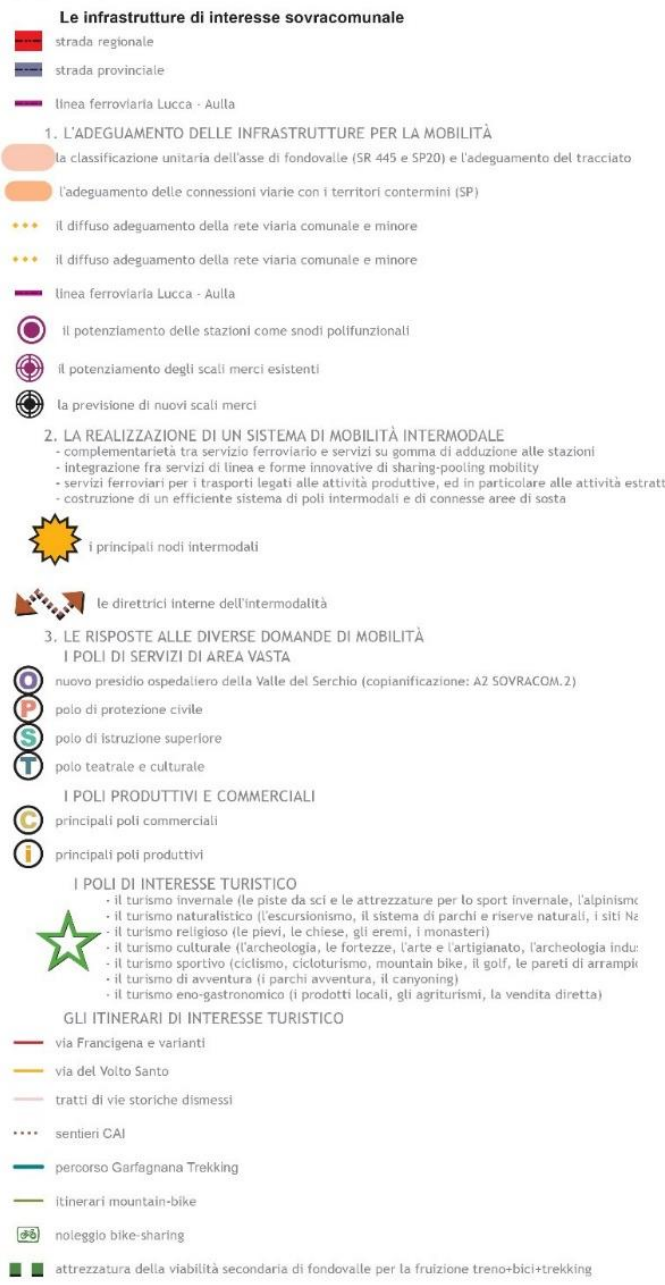

LE STRATEGIE PER LA RIQUALIFICAZIONE DEL SISTEMA INSEDIATIVO

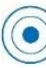

1. IL POTENZIAMENTO E L'EQUILIBRATA DISTRIBUZIONE TERRITORIALE DEI SERVIZI ESSENZIALI

- i poli di servizi di livello comunale

- $\quad$ presidi locali (esistenti da consolidare o da realizzare)

2. LA SALVAGUARDIA E LA VALORIZZAZIONE DEGLI INSEDIAMENTI STORICI

centro storic

centro storico
la salvaguardia dei caratteri originari deve coniugarsi con la conservazion

di importanti funzioni urbane, tali da preservare e qualificare la centralitita dei tessuti storici nel

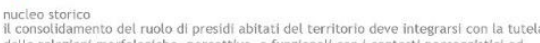

$\bullet$

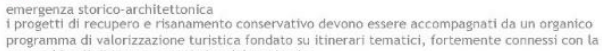
programma di valorizzazione turistica fondato si
rete ed i poli di interesse turistico del territoria

- alpegsia

3. IL RECUPERO DELLE AREE DEGRADATE E L'ADEGUAMENTO DEL PATRIMONIO EDILIZIO ESISTENTE - individuare e perimetrare gli ambitit urbani caratterizzati da degrado urbanistico $e$
socio economico ai sensi delliart.123 della LR $65 / 2014$ e definirire gli interventi socio economico al sensi dell'art. 123 della LR $65 / 2014$ e definirire gli interventi di
rigenerazione urbana per riqualificare e riorganizzare funzionalmente le aree dismesse e degradate -individuare i contesti insediativi marr ginalli interessati id fenomeni di spopolamento e di impoverimento
funzionale e promuovere, anche mediante meccanismi premiati, il recupero ed il riuso dei funzionale e promuovere, anche mediante meccanismi premiati, it recupero ed it riuso de
manufatti edilizi esistenti - definire, sulla base di protocolli ed azioni coordinate a livello dell Unione dei Comuni, le modalità per

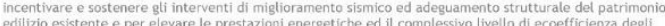

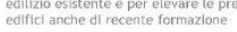
- predisporre un piano per labbattimento delle barriere architettoniche ed urbanistiche per
consentire laccesso al luoghi ed agl' spazi pubblici e cormunitari ed ai poli ii servizi e di consentire laccessa
interesse turistico

4. L'AMMODERNAMENTO INFRASTRUTTURALE E TECNOLOGICO DEGLI INSEDIAMENTI lazionale e diffuso miglioramento dei servizi e delle reti per lapprowigionamento idropotabt
per la depurazione, per l'aporovvigionamento energetico, per la raccolto e lo smaltimento

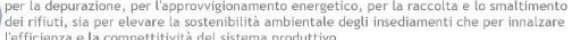
efficienza e ta compettitivita det sistema produttivo potenziamento dellinfrastruttura digitale, in linea con la Strategia Nazionale Aree Interne e gli obiettivi
NGN (Next Generation Networks fissati at 2020 dall'Agenda Digitale, anche al fine di accedere a
servizi nel settore scolastico e sanitario anche attraverso reti telematiche (telemedicicina, e-learning, etc.

Fuente: Unione dei Comuni della Garfagnana.

ACE, 16 (46) CC BY-ND 3.0 ES | UPC Barcelona, España | Accesibilidad y territorio histórico en Italia: estrategias resilientes para la revitalización, entre ferrocarriles secundarios y redes paisajísticas. DOI http://dx.doi.org/10.5821/ace.16.46.9890 
Figura 9. El Plan intermunicipal con valor de Plan estructural municipal y de Plan estratégico de la Union de los Municipios de la Garfagnana. P03 - I - strategie mobilità e sistema insediativo (Mapa)

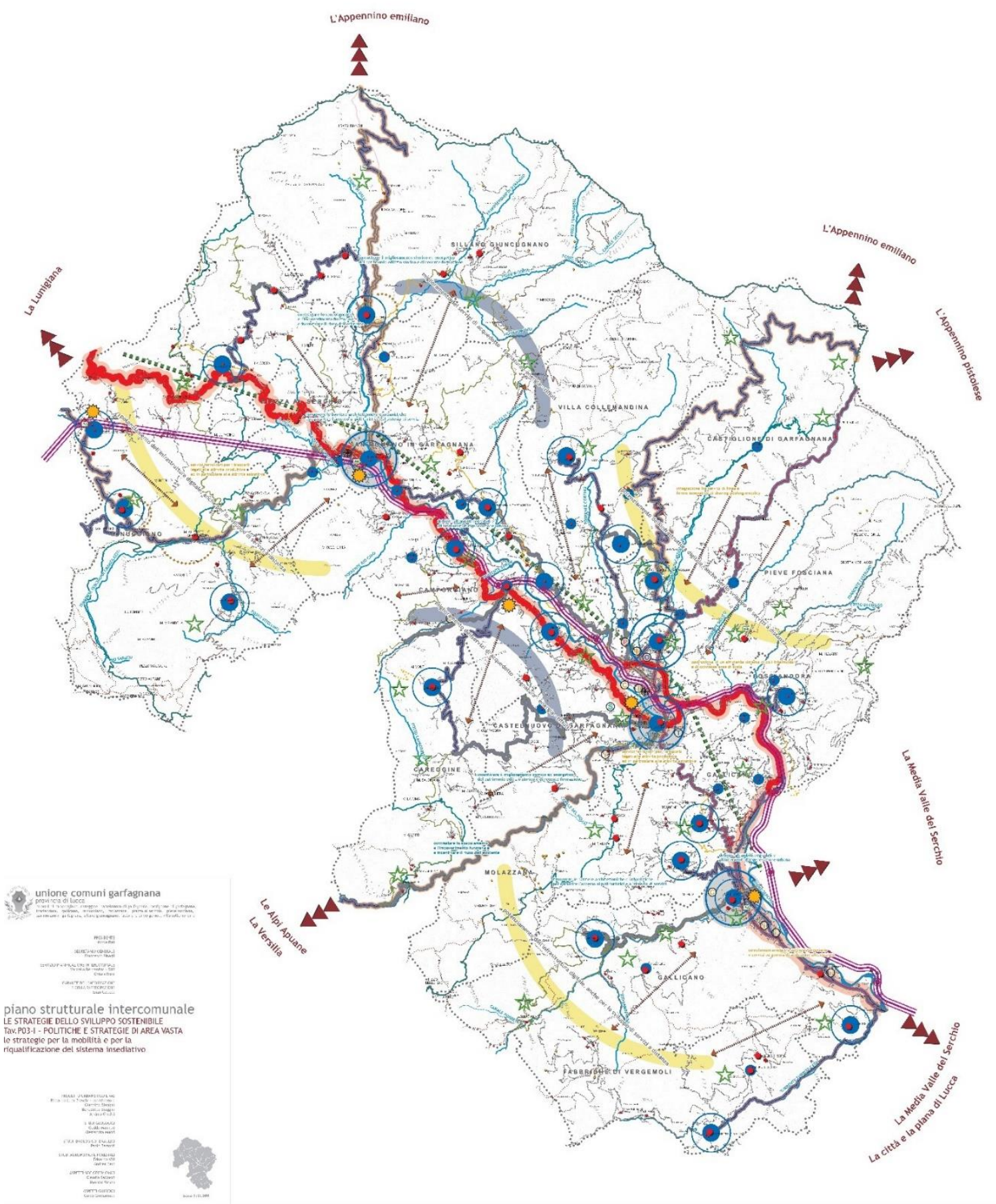

Fuente: Unione dei Comuni della Garfagnana. P03 - I - strategie mobilità e sistema insediativo (Carta).

La línea ferroviaria del valle Lucca-Aulla constituye la matriz de referencia para la estrategia de regeneración territorial potenciando las estaciones como "hubs polifuncionales", pues éstos se convierten en nudos de intercambio con servicios de transporte público local, sharing y poolingmobility y alquiler de bicicletas, y también en centros de información turística, así como en puntos

ACE, 16 (46) CC BY-ND 3.0 ES | UPC Barcelona, España | Accesibilidad y territorio histórico en Italia: estrategias 17 resilientes para la revitalización, entre ferrocarriles secundarios y redes paisajísticas. DOI http://dx.doi.org/10.5821/ace.16.46.9890 
de salida de rutas de valor cultural, como por ejemplo las directrices de trashumancia vertical, que redescubren relaciones territoriales y paisajísticas (Figura 9). .

Tabla 2. Clasificación de las necesidades de movilidad expresadas en las "Aree interne"

\begin{tabular}{|c|c|}
\hline Requerimientos generales & Requerimientos especificos \\
\hline \multirow{2}{*}{$\begin{array}{l}\text { Planificación y } \\
\text { programación de los } \\
\text { sistemas de transporte }\end{array}$} & $\begin{array}{l}\text { Promover la accesibilidad de los lugares, garantizando el derecho a la movilidad } \\
\text { de personas y oportunidades para el intercambio de bienes en el territorio, a } \\
\text { través de una visión integrada del sistema transporte-territorio mediante la } \\
\text { adopción de herramientas de planificación y programación del transporte } \\
\text { "estratégico" (escenario a } 10 \text { años). }\end{array}$ \\
\hline & $\begin{array}{l}\text { Promover la accesibilidad y el derecho a la movilidad en el territorio del espacio } \\
\text { interior con herramientas de programación y planificación de transporte } \\
\text { "tácticas" (Escenario de } 3 \text { años). }\end{array}$ \\
\hline \multirow{4}{*}{$\begin{array}{l}\text { Fortalecimiento y mejora } \\
\text { de la dotación de } \\
\text { transporte }\end{array}$} & $\begin{array}{l}\text { Incrementar la accesibilidad interna y externa al área mediante la adaptación de } \\
\text { la infraestructura de transporte. }\end{array}$ \\
\hline & $\begin{array}{l}\text { Promover la accesibilidad y el atractivo del Transporte Público Local con la } \\
\text { adaptación de los nodos de acceso, info-movilidad y renovación de flota. }\end{array}$ \\
\hline & $\begin{array}{l}\text { Fomentar la accesibilidad de los atractivos turísticos de la zona favoreciendo } \\
\text { oportunidades para un "uso sostenible" de los recursos ambientales y culturales. }\end{array}$ \\
\hline & $\begin{array}{l}\text { Apoyar el derecho a la movilidad de las personas con movilidad reducida debido } \\
\text { a condiciones físicas y/o socioeconómicas desfavorecidas. }\end{array}$ \\
\hline \multirow{5}{*}{$\begin{array}{l}\text { Desarrollo de los servicios } \\
\text { de transporte }\end{array}$} & $\begin{array}{l}\text { Facilitar la accesibilidad a los polos funcionales (escuela, trabajo) de la movilidad } \\
\text { "sistemática" de los residentes. }\end{array}$ \\
\hline & $\begin{array}{l}\text { Facilitar la accesibilidad a los centros funcionales (sanitarios, culturales, } \\
\text { deportivos, turísticos etc.) de la movilidad "no sistemática" de residentes y no } \\
\text { residentes (turistas, visitantes en general). }\end{array}$ \\
\hline & Apoyar el derecho a la movilidad de los usuarios con movilidad reducida. \\
\hline & $\begin{array}{l}\text { Promover la cohesión territorial de la "Área interna" y la accesibilidad desde y } \\
\text { hacia polos externos mediante el desarrollo de servicios de transporte, también } \\
\text { para turistas. }\end{array}$ \\
\hline & $\begin{array}{l}\text { Promover las oportunidades de uso sostenible de las áreas internas para los } \\
\text { residentes e los turistas fomentando los servicios "lentos o dulces" en las redes } \\
\text { peatonales y vías verdes. }\end{array}$ \\
\hline
\end{tabular}

Fuente: Snai-Mit-Isfort http://territori.formez.it/sites/all/files/areeinterne lineeguidatrasporti.pdf

\subsection{Infraestructuras históricas y puesta en valor del paisaje cultural. Núcleos históricos y directrices de trashumancia}

Poner el foco de interés en temas agrícolas - la reforma agraria primero y la "revolución verde" después - ha contribuido a obliterar esa cultura rural que desde tiempos ancestrales - entre los 8.000 y los 10.000 años a.C. - hasta finales del siglo XIX, ha dado razón causal a los asentamientos territoriales en formas más o menos codificadas. Durante los periodos de desarrollo económico y demográfico, y en una equilibrada y continua alternación, las actividades agrícolas han prevalecido en sus múltiples formas en la competición por el uso del territorio. Por el contrario, durante los periodos de incertidumbre, han vuelto a dominar los usos ganaderos hasta llegar a excesos patológicos. La oveja era un capital duradero fácil de transportar. Constituía una unidad básica de intercambio: "Los vínculos entre la actividad ganadera y el capitalismo se conocen hasta la saciedad:

ACE, 16 (46) CC BY-ND 3.0 ES | UPC Barcelona, España | Accesibilidad y territorio histórico en Italia: estrategias 18 resilientes para la revitalización, entre ferrocarriles secundarios y redes paisajísticas. DOI http://dx.doi.org/10.5821/ace.16.46.9890 


\section{ACE Architecture, City and Environment}

E-ISSN $1886-4805$

la derivación misma de la palabra pecunia, es decir del dinero, del pecus, del rebaño de ovejas, es noción corriente. Los ovinos se reproducían rápidamente como el dinero prestado» (Barberis, 1997). Con la aportación de diversos enfoques disciplinarios, los investigadores están redescubriendo la complejidad de ese mundo rural que durante mucho tiempo ha sido el eje de continuidad de la economía de los territorios y de las culturas populares: los cantos, los sonidos, la preparación de los alimentos, los usos compartidos del suelo, las distintas formas de asentamiento, la toponimia, los cultos, la fiscalidad, los oficios y la estructura social. Ordenadas en cadena a lo largo de directrices de desplazamiento estacional - la trashumancia - que une los pastos veraniegos del monte con los pastos invernales de las llanuras y los humedales costeros, vuelven a surgir hileras de enclaves que tocan esos lugares de excelencia de la historia y de la naturaleza que hoy constituyen recursos situados en los bordes de la región urbana.

Figura 10. Sistema geomorfológico de trashumancia tirrénica. Directrices de rutas de trashumancia.

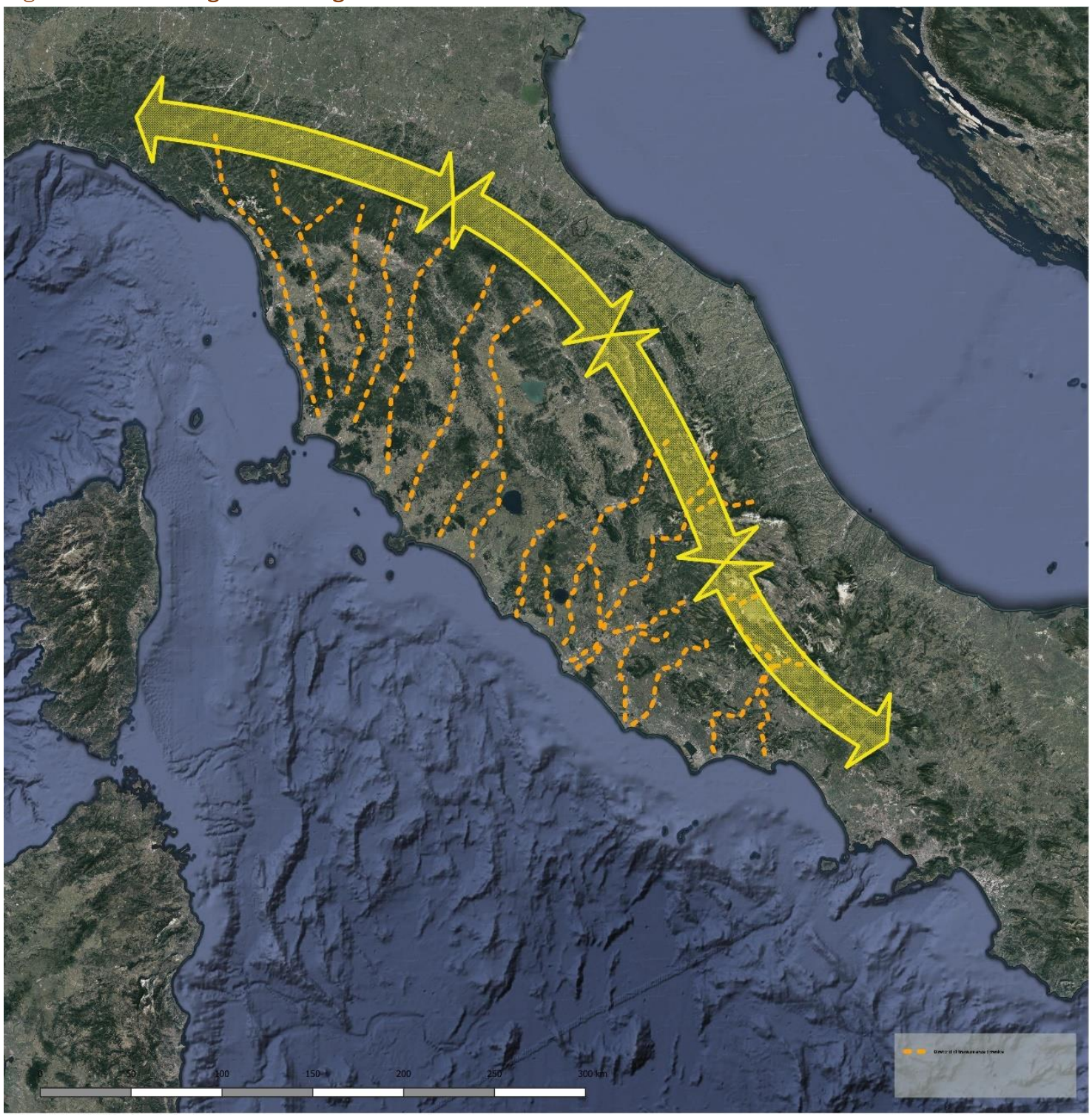

Fuente: Copyright: C. Valorani.

ACE, 16 (46) CC BY-ND 3.0 ES | UPC Barcelona, España | Accesibilidad y territorio histórico en Italia: estrategias resilientes para la revitalización, entre ferrocarriles secundarios y redes paisajísticas. DOI http://dx.doi.org/10.5821/ace.16.46.9890 


\section{ACE Architecture, City and Environment}

E-ISSN 1886-4805

En Italia existen distintas modalidades de trashumancia. Dejando de lado las tradiciones de las islas mayores, el trazado más famoso y perfectamente identificado es la "Dogana della Mena delle pecore" (Aduana de la trashumancia de las ovejas) que discurre por todo nuestro sur siguiendo una trayectoria longitudinal. Sin embargo, todo el arco alpino está caracterizado por la "monticazione", es decir la trashumancia vertical, aunque la vertiente tirrénica, desde la Toscana al Lacio hasta llegar a la Campania, se caracteriza por innumerables directrices de trashumancia transversales (Figura 10).

Directrices de trashumancia a las que corresponden unos itinerarios, en algunos tramos incluso trazados permanentes, a los que corresponde a su vez una territorialización de los flujos de movimiento que ha dado lugar a paisajes culturales complejos - a base de caminos, pastos, centros menores, iglesias, refugios y abrevaderos - que por definición cruzan varias unidades ambientalesgeobotánicas y, por tanto, propias de las infraestructuras históricas (Figura 11).

Figura 11. Rebaño pastando entre las gargantas y los acueductos romanos.Gallicano nel Lazio (2015)

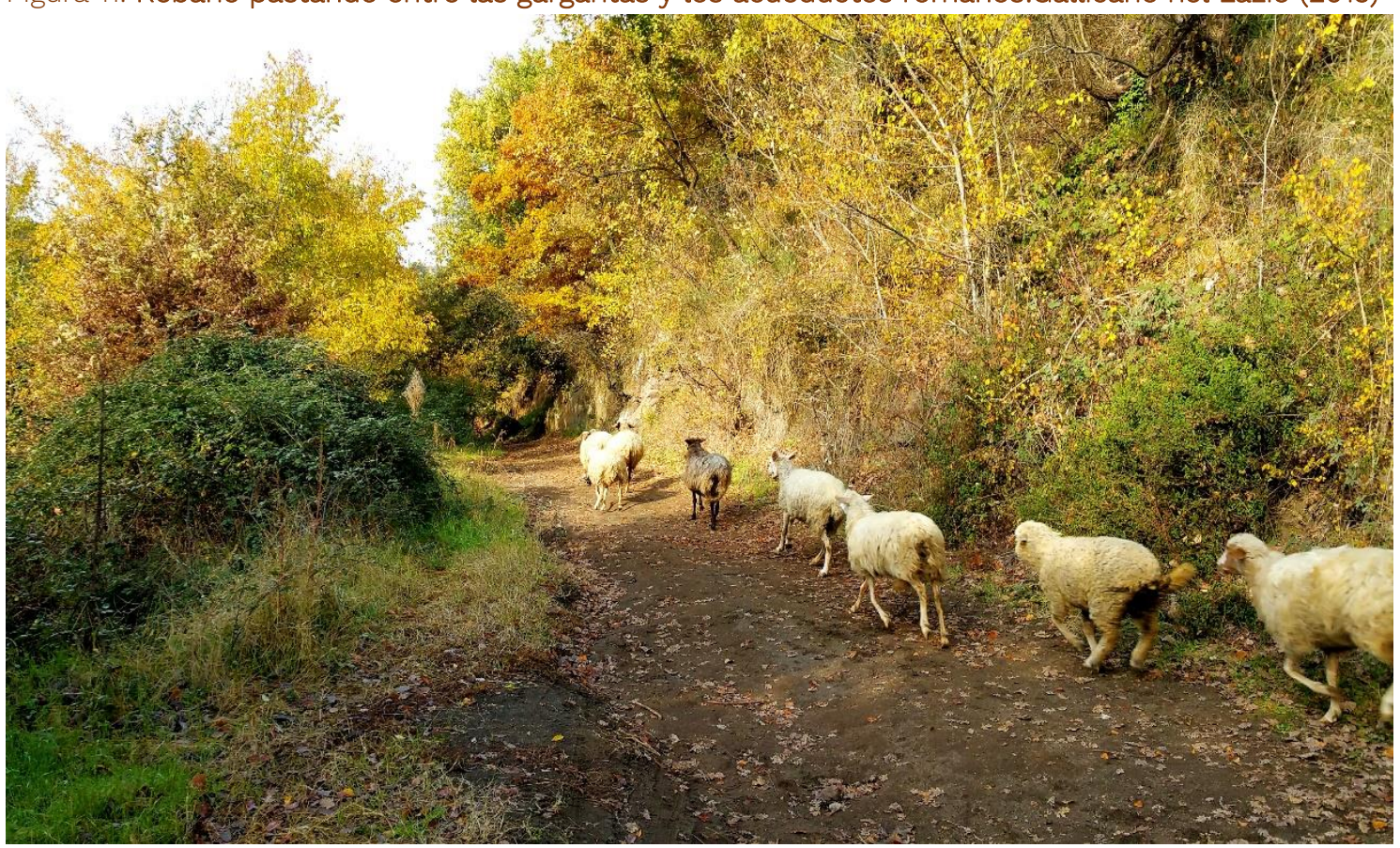

Fuente: C. Valorani

En el caso del Lacio, región que se caracteriza por un nivel muy elevado de heterogeneidad geobotánica (Almagià, 1966) se han podido identificar (Figura 12) por lo menos diez directrices (Valorani, 2018).

En relación a estos sistemas de asentamiento profundamente arraigados en las especificidades del entorno, es posible identificar, a través de un proceso de lectura multidisciplinario, algunos "distritos de paisaje" (Valorani y Marcozzi, 2016), que corresponden a sub-cadenas de territorio de las entidades locales del sector: Enti Parco e Comuni (Entidades Parque y Ayuntamientos). Éstos podrían organizarse según unas lógicas innovadoras (Mariano y Valorani, 2018) a través de protocolos de entendimiento o de uniones entre municipios que, trabajando con unas infraestructuras adecuadas, podrían encontrar actuaciones específicas de desarrollo en un primer momento, y de explotación turística después, con una integración más completa en la dinámica productiva de la región metropolitana.

ACE, 16 (46) CC BY-ND 3.0 ES | UPC Barcelona, España | Accesibilidad y territorio histórico en Italia: estrategias

resilientes para la revitalización, entre ferrocarriles secundarios y redes paisajísticas. DOI http://dx.doi.org/10.5821/ace.16.46.9890 


\section{ACE Architecture, City and Environment}

E-ISSN 1886-4805

Figura 11. La región metropolitana romana. Los ejes de trashumancia tirrénica

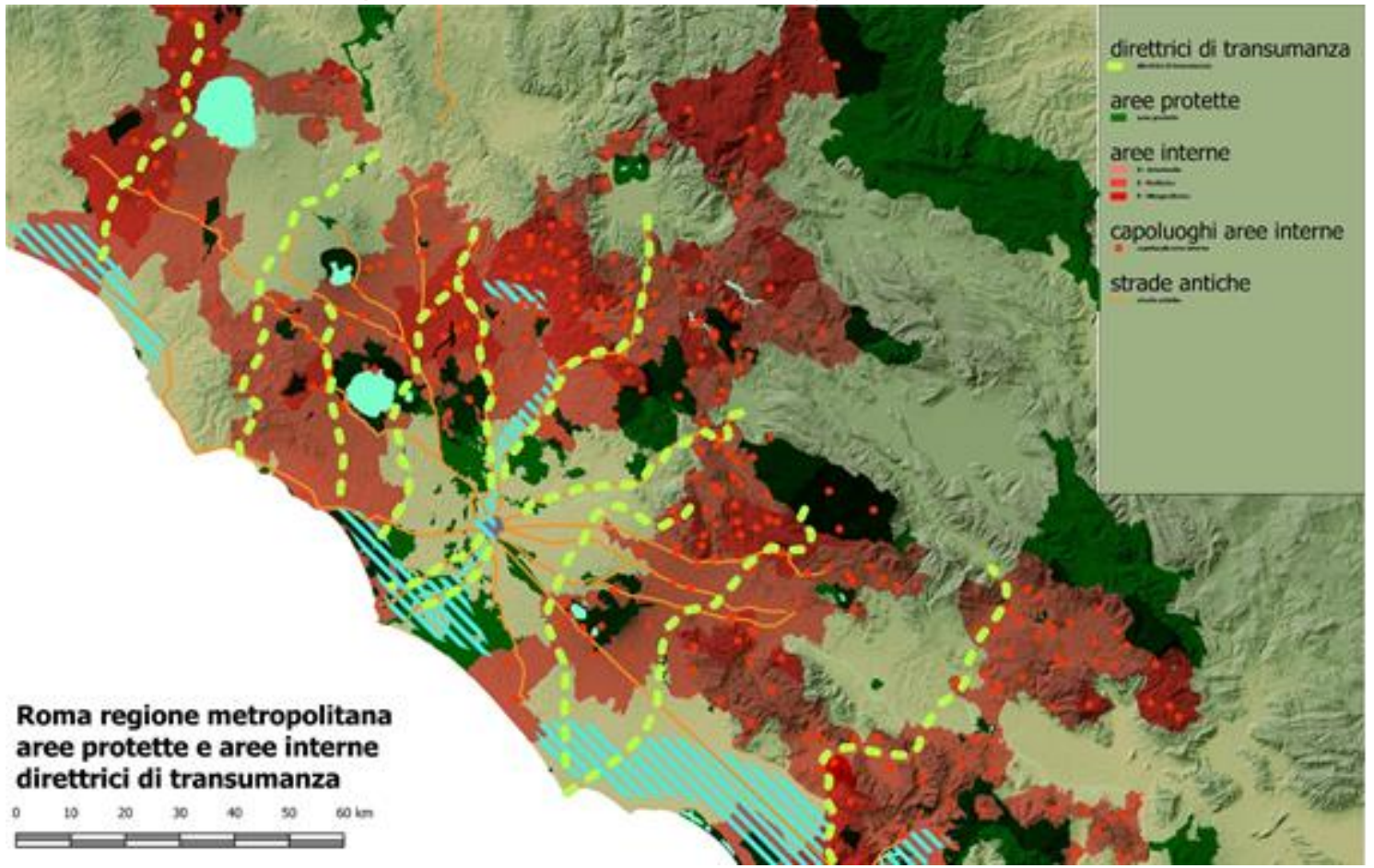

Fuente: C. Valorani.

\section{Conclusiones}

En la situación actual en que el país se encuentra ante una evidente crisis de obsolescencia del capital infraestructural, sobre todo ferroviario, pero que atañe también a la movilidad por carreteras muy transitadas así como por carreteras provinciales y municipales - ha llegado el momento de promover nuevas formas de movilidad sostenible que tengan en cuenta los caracteres específicos de los territorios y las nuevas prioridades para el país, que se reinterpretan también en las estrategias promovidas a nivel nacional y europeo y que son portadoras de herramientas asociativas y de nuevas sinergias entre los recursos (Lucatelli y Storti, 2019).

La complejidad del territorio histórico y las características de los ferrocarriles secundarios requieren soluciones específicas para los territorios internos, que incluyen tanto el relanzamiento del servicio de transporte ordinario como la reactivación de las líneas históricas, ya no utilizadas ni utilizables, mediante la transformación en vías verdes con el objetivo de la regeneración ecológica y valorización cultural del paisaje (Cfr. §3).

El re-equilibrio territorial es el único camino para afrontar los retos de la contemporaneidad. En la era post-industrial y de las nuevas tecnologías, la polarización en las grandes áreas urbanas es anacrónica. Las grandes industrias - las pocas que han sobrevivido - ya no están "en" las ciudades sino fuera, en áreas especializadas y cada vez con más frecuencia dotadas de calidad. Las grandes ciudades, las grandes conurbaciones, concentraciones humanas cada vez menos sostenibles, sobreviven porque son centros dispensadores de servicios y como tales se autoalimentan, de forma casi parasitaria. La revitalización de los centros urbanos menores (e históricos) y de los correspondientes territorios se configura como la opción principal a seguir, ya que nunca como ahora volver a "presidiar" el territorio aparece viable y no aplazable. Esta opción puede contar con las

ACE, 16 (46) CC BY-ND 3.0 ES | UPC Barcelona, España | Accesibilidad y territorio histórico en Italia: estrategias 21 resilientes para la revitalización, entre ferrocarriles secundarios y redes paisajísticas. DOI http://dx.doi.org/10.5821/ace.16.46.9890 
matrices infraestructurales históricas que constituyen elementos ordenadores de la morfología urbana y territorial, un sistema de flujos indispensables para la economía y el estado del bienestar y rutas privilegiadas de disfrute del paisaje. Pero puede contar también con un sistema de redes inmateriales (culturales, sociales, económicas) a través del cual relanzar el papel cultural, socioeconómico y ambiental central de los centros menores que en la época digital, que se ha potenciado de forma exponencial por la crisis actual pandémica, puede contar con la investigación y la experimentación de nuevas herramientas para acortar las distancias físicas.

Para poner en marcha unas políticas en este sentido, la chispa podría nacer de la "recuperación" del patrimonio edificatorio existente y de su "mantenimiento programado y constante", oportunidades para un mercado de la construcción que ya es asfíctico. De forma paralela, las políticas para la movilidad y los transportes deberían actuar adaptando las infraestructuras, rediseñando los mapas de los desplazamientos indispensables e incentivando formas de movilidad compartida e "inteligente" (modalidad de transporte integrado "privado-público-ligero", transporte bajo demanda, MaaS Mobility as a Service). De esta forma se garantizaría ese "Derecho a la movilidad" que integra el Derecho a la Ciudad (Lefebvre, 1968; Harvey, 1973, 2003)

En este contexto, es necesario un enfoque interdisciplinario que reconozca este sistema de infraestructuras y estaciones come una red funcional, fisica-morfologica y paesajística de lugares de enlace, de intercambio, de integración e inclusión (Borja y Muxi, 2003; Parcerisa et al, 2013; Parcerisa et al., 2019). Una estructura de espacio público mulitescalar que representa entonces la referencia para fortalecer las relaciones materiales e inmateriales entre los centros menores y para reactivar las conexiones con los territorios más dinámicos del país.

La coordinación con la planificación territorial y urbana, que permitiría la redistribución de los servicios y del equipamiento público, y la difusión de formas institucionales de cooperación entre los pequeños municipios (ya previstos hoy, como la "Unión de Municipios") contribuirían al relanzamiento de las actividades económicas locales, íntegradas y sostenibles. Si a esto le sumamos las oportunidades relacionadas con los distintos "matices" de las normas comunitarias sobre la liberalización del mercado de transportes, empezando por el ferroviario, podemos estar seguros de que desplazar la atención de los grandes centros urbanos (pocos, congestionados y saturados) a los "territorios periféricos" es una opción viable y remunerativa.

Reactivar los "territorios interiores" significa reactivar relaciones económicas, sociales y culturales. Significa volver a traer población activa que pueda "mantener" el territorio entendido como fuente de vida. Y éste debería ser el objetivo central de un auténtico "desarrollo sostenible e inclusivo".

\section{Agradecimientos}

La actividad de investigación que se ilustra en este artículo es parte de una colaboración científica entre la Sapienza Università di Roma y la Università degli Studi di Roma Tre, financiada por Sapienza.

\section{Autoría}

Este trabajo es el resultado de una actividad de investigación conjunta. Sin embargo, la autoría de los apartados se puede atribuir de la siguiente forma: los § 1, 4 y 4.1 a Chiara Ravagnan, el $\S 2$ a Bruno Monardo, los $\S 3$ y 5 a Mario Cerasoli, el $\S 4.2$ a Carlo Valorani.

Conflicto de intereses: Los autores declaran que no hay conflicto de intereses.

ACE, 16 (46) CC BY-ND 3.0 ES | UPC Barcelona, España | Accesibilidad y territorio histórico en Italia: estrategias 


\section{Bibliografía}

AA. VV. (2017). Profecy - Processes, Features and Cycles of Inner Peripheries in Europe. Final Report. Espon program EU. Recuperado de https://www.espon.eu/sites/default/files/attachments/D5\%20 Final\%20Report\%20PROFECY.pdf

Al Dwairi A. (2020), Re-valuing canals. Valuation of ecosystem services provided by the Smart Canal project, Final report Master of Urban Climate \& Sustainability (MUrCS), Glasgow Caledonian University, UK; LAB University of Applied Sciences, Finland; University of Huelva, Spain.

Almagià, R. (1966). Lazio. En Le Regioni d'Italia, XI, Torino, Italia: UTET.

Amato, C., de Ureña, J. M., Ravagnan, C., Rossi, F. (2019). Derecho a la movilidad y rutas de resiliencia. Reutilización y relanzamiento de ferrocarriles menores para la regeneración de territorios frágiles en Italia y España. En CTV 2019 Proceedings: XIII International Conference on Virtual City and Territory: "Challenges and paradigms of the contemporary city". (p. 8527). Barcelona: España. DOI: http://dx.doi.org/10.5821/ctv.8527

Amato, C., Bevilacqua, G., Ravagnan, C. (2020), The abandoned railway heritage: from problem to opportunity for the regeneration of minor historic centres. En Bevilacqua, C. et al. (eds.), New Metropolitan Perspectives. Knowledge Dynamics and Innovation driven Policies Towards Urban and Regional Transition, 2, 1735-1745. Springer. DOI: https://doi.org/10.1007/978-3-030-48279-4 164

Alvarez Mora, A. (2019). Reflexiones urbanísticas, En Dossier Ciudades, 4. Recuperado de: https://iuu.uva.es/publicaciones/dossier-ciudades/reflexiones-urbanisticas-un-pensamiento-declase-para-el-entendimiento-de-la-ciudad/

ANCSA - Associazione Nazionale Centri Storico-Artistici, (1990). Carta di Gubbio, Gubbio, Italia.

Barberis, C. (1997). Le campagne italiane. Da Roma Antica al settecento. Bari, Italia: Laterza.

Barca, F. (2009). An agenda for a reformed cohesion policy: A place-based approach to meeting European Union challenges and expectations, Brussels: EU Commission.

Barca, F., Casavola, P. y Lucatelli S. (2014). A strategy for inner areas in italy: definition, objectives, tools and governance. En Materiali UVAL, 31. Recuperado en: https://www.agenziacoesione.gov.it/wpcontent/uploads/2020/07/MUVAL 31 Aree interne ENG.pdf

Borja, J. y Muxi, Z. (2003). El espacio público. Ciudad y ciudadanía. Barcelona, España: Electa.

Briatore, S. (2011). Valorizzazione dei centri storici minori. Strategie d'intervento. Reggio Emilia, Italia: Diabasis.

Caulls A. (1999), Railways as World Heritage Sites, Paris: ICOMOS.

Carubia, A. et al. (2015). Territori interni. La pianificazione integrata per lo sviluppo circolare: metodologie, approcci, applicazioni per i nuovi cicli di vita. Roma, Italia: Aracne.

Cerasoli M. (2015). Politiche ferroviarie, modelli di mobilità e territorio. Le ferrovie italiane nell'epoca della pseudo liberalizzazione. Roma, Italia: Aracne.

ACE, 16 (46) CC BY-ND 3.0 ES | UPC Barcelona, España | Accesibilidad y territorio histórico en Italia: estrategias 23 resilientes para la revitalización, entre ferrocarriles secundarios y redes paisajísticas. DOI http://dx.doi.org/10.5821/ace.16.46.9890 
Cerasoli, M. (2016). Cities of the world, a world of suburbs. Transformations of 'settlements rules' and 'forms of living' in contemporary Latin America (among globalization, cars and television). Czasopismo Techniczne Architektura - Technical Transactions Architecture. 113, 2-A, 35-50. DOI https://doi.org/10.4467/2353737XCT.16.175.5786

Cerasoli, M. (2017). La recuperación de los centros históricos menores, hacia las "historical small smart cities". ACE: Architecture, City and Environment, 1(33): 155-180, DOI: https://doi.org/10.5821/ace.11.33.5153

Cerasoli, M. y Mattarocci, G. (2019). Secondary railways and inner areas in Italy: urban planning and economic opportunities. In XIII CTV 2019 Proceedings: XIII International Conference on Virtual City and Territory: "Challenges and paradigms of the contemporary city" (p. 8746). Barcelona, España. DOI http://dx.doi.org/10.5821/ctv.8746

Certu - Ministère de l'Ecologie, de Développement durable, des Transports et du Logement. (2011). Accessibilité dans 11 villes européennes. Lyon, France: Ed. CERTU.

Cervellati, P.L. (2009). Minori e maltrattati La sorte dei piccoli centri storici. En Bollettino Italia Nostra, 445, p.11-13.

Choay F. (1992). L'invenzione del patrimonio storico. En Rassegna di architettura e urbanistica, 80-81. Conlin M. V. y Bird G. R. (eds. 2014), Railway Heritage and Tourism: Global Perspectives. Bristol, Buffalo, Toronto: Channel View Publications.

Comisión de la Comunidades Europeas. (2009). Comunicación de la Comisión al Parlamento Europeo, al Consejo, al Comité Económico y Social Europeo y al Comité de las Regiones, Plan de Acción de Movilidad Urbana, $\operatorname{COM}(2009) \quad$ 490, Bruselas. Recuperado de https://ec.europa.eu/transparency/regdoc/rep/1/2009/ES/1-2009-490-ES-F1-1.pdf

Corboz, A. (1983). The Land as palimpsest. Diogenes, 121, 12-34. DOI: https://doi.org/10.1177/039219218303112102

Di Venosa, M. y Morrica, M. (2018). Rigenerare territori fragili. Roma, Italia: Aracne.

Dupuy, G. (1991). L'urbanisme des réseaux. Théories et methodes. Paris, France: Colin.

García-Mayor, C., Martí, P., Castaño, M. y Bernabeu-Bautista, Á. (2020), The Unexploited Potential of Converting Rail Tracks to Greenways: The Spanish Vías Verdes, Sustainability, 12(3), 881. DOI: https://doi.org/10.3390/su12030881

Harvey, D. (2003). Social Justice and the City. Athens, USA: University of Georgia.

Harvey, D. (2003). The right to the city, International Journal of Urban and Regional Research, 27(4), 939-941. DOI: https://doi.org/10.1111/j.0309-1317.2003.00492.x

Lefebvre, H. (1968). Le Droit à la ville, Paris, France: Anthropos.

Lucatelli, S. y Storti, D. (2019). La strategia nazionale aree interne e lo sviluppo rurale: scelte operate e criticità incontrate in vista del post 2020. En Agriregionieuropa, 56. Recuperado de https://agriregionieuropa.univpm.it/it/content/article/31/56/la-strategia-nazionale-aree-interne-e-losviluppo-rurale-scelte-operate-e

ACE, 16 (46) CC BY-ND 3.0 ES | UPC Barcelona, España | Accesibilidad y territorio histórico en Italia: estrategias 24 resilientes para la revitalización, entre ferrocarriles secundarios y redes paisajísticas. DOI http://dx.doi.org/10.5821/ace.16.46.9890 
Litman, T. A. (2014). Evaluating Accessibility for Transportation Planning. Measuring People's Ability to Reach Desidered Goods and Activities. Victoria, Canada: Victoria Transport Policy Institute.

Mariano, C., Valorani, C. (2018). Territori metropolitani e pianificazione intercomunale. Milano, Italia: FrancoAngeli.

Mattarocci, G. (2020). Il potenziale economico delle società ferroviarie che operano nelle aree interne: un'analisi di bilancio. En Ravagnan, C. y Amato, C. Percorsi di resilienza. Rilancio e riuso delle ferrovie in dismissione nei territori fragili tra Italia e Spagna (pp. 359-372). Roma, Italia: Aracne.

Mibact - Ministero per i beni e le attività culturali e per il turismo, 2020. Avviso pubblico relativo alla selezione di interventi finalizzati alla riqualificazione e valorizzazione turistico-culturale dei Comuni delle regioni: Basilicata, Calabria, Campania, Puglia e Sicilia (Gazzetta Ufficiale V Serie Speciale Contratti Pubblici n. 24 del 28/02/2020). Recuperado en: https://www.beniculturali.it/comunicato/bando-borghi-e-centri-storici

Monardo, B. (2014). Accessibility planning per nuove strategie di rigenerazione insediativa. En Ricci M., Ricci, M., Battisti, A. y Monardo, B. (eds.). (2014). / Borghi della Salute. Firenze, Italia: Altralinea.

Gilmartín, M. A. (2008). Ambientes escolares. En J. A. Aragonés y M. Amérigo. (Eds.), Psicología ambiental (pp. 221-237). Madrid, España: Pirámide.

Mongin, O. (2013). La ville des flux. L'envers et l'endroit de la mondialisation urbaine. Paris, France: Fayard.

OECD. (2013). Rural-Urban Partnership: An Integrated Approach to Economic Development. Paris, France: OECD.

Offner, J. M., Pumain, D. (1996). Réseaux et territoires. Significations croisées, Saint-Etienne, France: Aube.

Palazzo, A. L. (2017). Centri minori e cultura della complessità. Problematiche, prospettive, traiettorie di riuso. ACE: Architecture, City and Environment, 11 (33): 213-218. DOI: http://dx.doi.org/10.5821/ace.11.33.5157.

Parcerisa, J., Crosas, C. (2013). Barcelona enllaços, enlaces, links. Barcelona, España: LUB.

Parcerisa, J., Crosas, C. y Clua, Á. (2019). Barcelona Links: Application of Research by Design to the Study of Urbanism. Technology / Architecture + Design, 3:1, 36-38, DOI: https://doi.org/10.1080/24751448.2019.1571796

Pignatti, L. et al. (Eds). (2019). IFAU '18 - Territori fragili / Fragile territories. Paesaggi_Città_Architetture / Landscapes_Cities_Architecture. Roma, Italia: Gangemi.

Ravagnan, C. (2019). Rigenerare le città e i territori contemporanei. Prospettive e riferimenti operativi per la sperimentazione, Roma, Italia: Aracne.

Ravagnan, C. y Amato, C. (2020). Percorsi di resilienza. Rilancio e riuso delle ferrovie in dismissione nei territori fragili tra Italia e Spagna. Roma, Italia: Aracne.

ACE, 16 (46) CC BY-ND 3.0 ES | UPC Barcelona, España | Accesibilidad y territorio histórico en Italia: estrategias 
Ravagnan, C. et al. (2021). Rutas de resiliencia en Italia y España: relanzamiento y reutilización de ferrocarriles en territorios frágiles. ACE: Architecture, City and Environment, 15(45), 10369. DOI: http://dx.doi.org/10.5821/ace.15.45.10369

Sellari, P. (2011). Uno sguardo alle ferrovie italiane nell'Ottocento postunitario. Studi e Ricerche socioterritoriali, 1-2011, p. 99-122. Recuperado de https://studiericerche.org/wpcontent/uploads/2020/07/Sellari.pdf

Taylor P. (2015). What factors make rail trails successful as tourism attractions? Developing a conceptual framework from relevant literature, Journal of Outdoor Recreation and Tourism, 12, 8998. DOI: https://doi.org/10.1016/j.jort.2015.11.005

Touraine, A. (2008). La globalizzazione e la fine del sociale. Milano, Italia: Il Saggiatore.

Unesco. (2011). Recommendation on the Historic Urban Landscape.

Valorani C. y Marcozzi E. (2016). Landscape Districts along the «Via Francigena in the South»: the Monti Lepini area". En Gambardella C. (ed). World Heritage and Degradation Smart Design, Planning and Technologies (pp. 1718-1725). Napoli, Italia: La scuola di Pitagora editrice.

Valorani, C. (2018). La rete europea dei percorsi di transumanza: il caso dell'area laziale. Urbanistica informazioni, 278 S.I., 112-116.

World Health Organization. (2001). Classification internationale du fonctionnement, du handicap et de la santé: CIF. Genève, Suisse: Organisation mondiale de la Santé. Recuperado de https://apps.who.int/iris/handle/10665/42418

ACE, 16 (46) CC BY-ND 3.0 ES | UPC Barcelona, España | Accesibilidad y territorio histórico en Italia: estrategias 